Research Article

\title{
Comparison of Multiple Surface Ocean Wind Products with Buoy Data over Blue Amazon (Brazilian Continental Margin)
}

\author{
Vitor Paiva $\mathbb{D},{ }^{1}$ Milton Kampel $\mathbb{D},{ }^{1}$ and Rosio Camayo $\mathbb{D}^{2}$ \\ ${ }^{1}$ Earth Science Coordination, Earth Observation and Geoinformatics, National Institute for Space Research, \\ Sao Jose dos Campos 12227-010, Brazil \\ ${ }^{2}$ Earth Science Coordination, Numerical Modelling of the Earth System, National Institute for Space Research, \\ Cachoeira Paulista 12630-000, Brazil \\ Correspondence should be addressed to Milton Kampel; milton.kampel@inpe.br
}

Received 10 December 2020; Revised 24 May 2021; Accepted 31 August 2021; Published 14 September 2021

Academic Editor: Maria Ángeles García

Copyright (C) 2021 Vitor Paiva et al. This is an open access article distributed under the Creative Commons Attribution License, which permits unrestricted use, distribution, and reproduction in any medium, provided the original work is properly cited.

\begin{abstract}
Remote sensing data for space-time characterization of wind fields in extensive oceanic areas have been shown to be increasingly useful. Orbital sensors, such as radar scatterometers, provide data on ocean surface wind speed and direction with spatial and temporal resolutions suitable for multiple applications and air-sea studies. Even considering the relevant role of orbital scatterometers to estimate ocean surface wind vectors on a regional and global scale, the products must be validated regionally. Six different ocean surface wind datasets, including advanced scatterometer (ASCAT-A and ASCAT-B products) estimates, numerical modelling simulations (BRAMS), reanalysis (ERA5), and a blended product (CCMP), were compared statistically with in situ measurements obtained by anemometers installed in fifteen moored buoys in the Brazilian margin ( 8 buoys in oceanic and 7 in shelf waters) to analyze which dataset best represents the wind field in this region. The operational ASCAT wind products presented the lowest differences in wind speed and direction from the in situ data $\left(0.77 \mathrm{~ms}^{-1}<\mathrm{RMSE}_{\mathrm{spd}}<1.59 \mathrm{~ms}^{-1}\right.$, $0.75<R_{\mathrm{spd}}<0.96,-0.68 \mathrm{~ms}^{-1}<$ bias $_{\mathrm{spd}}<0.38 \mathrm{~ms}^{-1}$, and $12.7^{\circ}<\mathrm{RMSE}_{\mathrm{dir}}<46.8^{\circ}$ ). CCMP and ERA5 products also performed well in the statistical comparison with the in situ data $\left(0.81 \mathrm{~ms}^{-1}<\mathrm{RMSE}_{\mathrm{spd}}<1.87 \mathrm{~ms}^{-1}, \quad 0.76<R_{\mathrm{spd}}<0.91\right.$, $-1.21 \mathrm{~ms}^{-1}<\operatorname{bias}_{\mathrm{spd}}<0.19 \mathrm{~ms}^{-1}$, and $\left.13.7^{\circ}<\mathrm{RMSE}_{\mathrm{dir}}<46.3^{\circ}\right)$. The BRAMS model was the one with the worst performance $\left(\mathrm{RMSE}_{\mathrm{spd}}>1.04 \mathrm{~m} \cdot \mathrm{s}^{-1}, R_{\mathrm{spd}}<0.87\right.$ ). For regions with a higher wind variability, as in the southern Brazilian continental margin, wind direction estimation by the wind products is more susceptible to errors $\left(\operatorname{RMSE}_{\mathrm{dir}}>42.4^{\circ}\right.$ ). The results here presented can be used for climatological studies and for the estimation of the potential wind power generation in the Brazilian margin, especially considering the lack of availability or representativeness of regional data for this type of application.
\end{abstract}

\section{Introduction}

Ocean surface wind is one of the main drivers of several oceanic, atmospheric, and climate processes, thus being an important indicator of climate change [1]. Ocean surface wind vector variability is intrinsically linked to that of oceanic processes, such as coastal upwelling [2, 3], primary productivity $[4,5]$, deep water formation [6,7], advective volume transport, air-sea momentum, and heat fluxes [8-11]. Having the ability to measure wind speed and direction with high accuracy becomes essential to these processes' studies, also considering the impacts on weather forecasting, navigation, marine engineering, and offshore wind energy $[1,12,13]$.

The vast extension of the global ocean imposes technical and financial limitations on in situ ocean surface winds sampling, which is necessary and valuable in remote sensing calibration and validation process. Direct measurements are acquired by anemometers on moored buoys, research cruises, and vessels of opportunity, or by light detection and ranging (Lidar) sensors, providing precise and accurate data. However, these techniques are limited to point measurements that are not able to provide satisfactory spatial and temporal coverage to resolve variability at different scales [14]. 
Today, more than 10 global and regional atmospheric reanalysis and wind products are available for the scientific community [15]. Numerical prediction models are capable of simulating ocean surface winds on a global scale but depend on the existing knowledge about the physical processes and on the availability of data used to parametrize the initial conditions of the simulations $[16,17]$. In weather prediction, the ability to make a skilful forecast requires both realistic representation of the atmosphere by numerical models and accurate initial conditions [18].

Reanalysis products integrate simulated data from numerical prediction models with atmospheric, oceanic, and other measurements, but with relatively low spatial resolutions (250 to $\sim 31 \mathrm{~km}$ ). This can be insufficient to adequately represent small and mesoscale meteorological features and accurately characterize local wind regimes [19]. Offshore wind blended products usually consider a first guess of the wind vector as the background and assimilate multiple sources of measured wind data from buoys, ships, and satellites [20].

Orbital remote sensors provide wind data on a global scale, covering remote regions normally characterized by the availability of sparse in situ data, with relatively good accuracy and high spatial and temporal resolution [21]. Ocean surface wind vectors with high spatial and temporal resolution obtained by spaceborne scatterometers are utilized in various fields of meteorology, oceanography, and climate studies $[22,23]$. Surface wind and stress fields derived from scatterometer observations can be applied to drive ocean circulation models on various scales and can also be assimilated into regional and global numerical weather prediction models $[21,24]$. These data have also been used to infer about offshore wind energy potential [20, 25].

Scatterometers measure the radar cross section of the ocean surface, and numerical inversion of the geophysical model function (GMF) yields the scatterometer wind measurement. The present constellation of scatterometers maps the surface wind field globally, with a typical spatial resolution of $25-12.5 \mathrm{~km}$ [26], and has been successfully used in weather forecasting applications [27], long-term climate studies [28], and air-sea interactions [29]. The main limitations of scatterometers are contamination by rain (depending on the frequency of the transmitted signal), lack of data near the coast (typically within $15 \mathrm{~km}$ ), and poor temporal sampling [21].

Although the number of space-borne scatterometers is increasing in recent years, regional validation of wind products from different scatterometers $[30,31]$ and producers [32] remains a challenge [33]. Moored ocean buoys provide the absolute calibration reference for satellite wind retrievals [22]. While the development of GMF and wind retrieval algorithms rely on many inputs (numerical models, wind retrievals for other satellites, statistical constraints, etc.), finalized satellite wind retrievals always need to be verified by comparisons with buoys.

Several studies evaluated the accuracy of wind products over the ocean comparing them with in situ measurements globally and regionally $[19,24,34-46]$. In general, these authors observed good agreement (mean square error, bias, and correlations) between wind products and in situ measurements. However, significant systematic differences do exist in the wind products derived from different scatterometers [20, 30, 31] and from different producers [32], which may result in detrimental impacts on different applications, if unknown. Therefore, characterizing errors and inconsistencies among different wind products is important, not only for guiding wind product users, but also to motivate research by the producers to solve inconsistencies problems.

The Brazilian oceanic area represented by the "Territorial Sea" and the "Exclusive Economic Zone" corresponds to approximately 3.6 million $\mathrm{km}^{2}$. If the "Extended, External, Jurisdictional" or "Legal Continental Shelf" claimed to the Commission on the Limits of the Continental Shelf of the United Nations in three "Revised Partial Proposals" for the outer limit of the Brazilian Continental Shelf (2.1 million $\mathrm{km}^{2}$ ) is added to this area, the total oceanic area called the "Blue Amazon" may be approximately 5.7 million $\mathrm{km}^{2}$. This immense oceanic area contains an enormous amount of economically, socially, and strategically relevant resources and is extremely important for climate stability and environmental quality of the adjacent coast [47].

The South Atlantic Subtropical Anticyclone (SASA) is the main feature of the atmospheric circulation over the South Atlantic Ocean, with a seasonal variability extending over south-eastern Brazil during the austral winter and retracting eastward during the summer [48]. SASA contributes with northeast winds to the Brazilian continental margin that are more constant during austral spring and summer [49].

Over the Tropical Atlantic, the Intertropical Convergence Zone (ITCZ) associated with the confluence zone of the northeast and southeast trade winds migrates seasonally from its most northerly position, around $\sim 10^{\circ} \mathrm{N}$ in AugustSeptember, to its southerly position, around $\sim 2^{\circ} \mathrm{S}$ in MarchApril in the Atlantic Ocean [50, 51]. Associated with the mesoscale oscillations, the frontal systems move with cyclones and post-frontal anticyclones, changing the fields of atmospheric pressure, wind, and other atmospheric variables along their trajectory [52]. Between $30^{\circ} \mathrm{S}$ and $50^{\circ} \mathrm{S}$, the zones with the highest occurrence of cold fronts are concentrated on the South-Southwestern Atlantic, mainly in the coastal areas of Argentina and Uruguay [53]. The south and south-eastern coasts of Brazil and the region between the extreme south of Brazil and the coast of Argentina are favourable regions for the formation of cyclones [54]. These systems cause strong winds, precipitation and decrease in temperature [55]. In this region, the atmospheric circulation is characterized, on a synoptic scale, mainly by the movement of transient systems such as cyclonic vortices, frontal systems, and the South Atlantic Convergence Zone (SACZ) [56].

For better understanding the wind regimes on the Brazilian continental margin, and to aid in decision-making for the installation of offshore wind turbines, there is a need to conduct a study that contemplates this vast oceanic area. The dataset used must be adequate to characterize the spatial and temporal variability of the local wind fields, and also to estimate the potential offshore wind energy production. 
This study aims to evaluate and compare different alternative sources of offshore wind data, including the Advanced SCATterometer (ASCAT) on board MetOP-A (ASCAT-A) and MetOP-B (ASCAT-B) European satellites, the Cross-Calibrated Multi-Platform wind product, the European Centre for Medium-Range Weather Forecasts ERA5 Reanalysis, and numerical simulations from the Brazilian Regional Atmospheric Modelling System (BRAMS/CPTEC) with in situ ocean surface wind measurements, aiming to analyze the capacity of these wind data sources in describing the wind field in the Blue Amazon region.

\section{Materials and Methods}

2.1. Buoy Wind Data. Time series of in situ wind data measured by anemometers installed in 15 oceanographic buoys moored on the Brazilian continental shelf and in deeper oceanic waters were obtained from the Brazilian National Buoy Program (PNBOIA) and the Prediction and Research Moored Array in the Tropical Atlantic (PIRATA) project, respectively. The geographical locations and summarized information regarding these buoys are presented in Figure 1 and Table 1, respectively.

Eight PIRATA buoys used in this study are moored at depths between 1,500 and $6,000 \mathrm{~m}$ and are equipped with a R. M. Young mechanical anemometer, model 05103 (http:// www.youngusa.com/products/11/5.html), or with a Gill WindSonic ultrasonic anemometer (http://gillinstruments. com/data/datasheets/windsonic-1405-027-iss7.pdf), installed $4 \mathrm{~m}$ above sea level. Wind direction is measured with a Sparton SP3004D compass (https://sparton.com/) or an EG\&G fluxgate compass model 63764 or KVH LP101-5 (https://www. pmel.noaa.gov/gtmba/sensor-specifications). Data with a 10 minute temporal resolution, containing measurements since 1997, are available from NOAA's Pacific Marine Environmental Laboratory (https://www.pmel.noaa.gov/tao/drupal/ disdel/).

Seven PNBOIA buoys used in this study are moored close to the continental shelf break ( $200 \mathrm{~m}$ isobath). The PNBOIA data, maintained by the Brazilian Navy Hydrography Centre, are available on the Internet (https://www. marinha.mil.br/chm/dados-do-goos-brasil/pnboia-mapa).

Time series of wind data are provided with hourly time resolution. The temporal coverage of the data ranges from $04 / 2009$ to $11 / 2018$. The buoys contain 2 anemometers, one mechanical installed at $4.7 \mathrm{~m}$ above sea level (used as the main reference) and another ultrasonic sensor installed at $3.7 \mathrm{~m}$. More information about the sensors of each buoy can be found at the same Internet address for data access.

To adjust the wind measured by the buoys to $10 \mathrm{~m}$, a steady-state neutrally stable logarithmic vertical wind profile relation was considered. In this case, the wind speed $(U)$ at height $z$ is given by

$$
U(z)=\frac{u^{*}}{k} \ln \left(\frac{z}{z_{0}}\right),
$$

where $k$ is the von Kármán constant $(k=0.41)$ and $z_{0}$ is the surface roughness that depends on the friction velocity $\left(u^{*}\right)$,

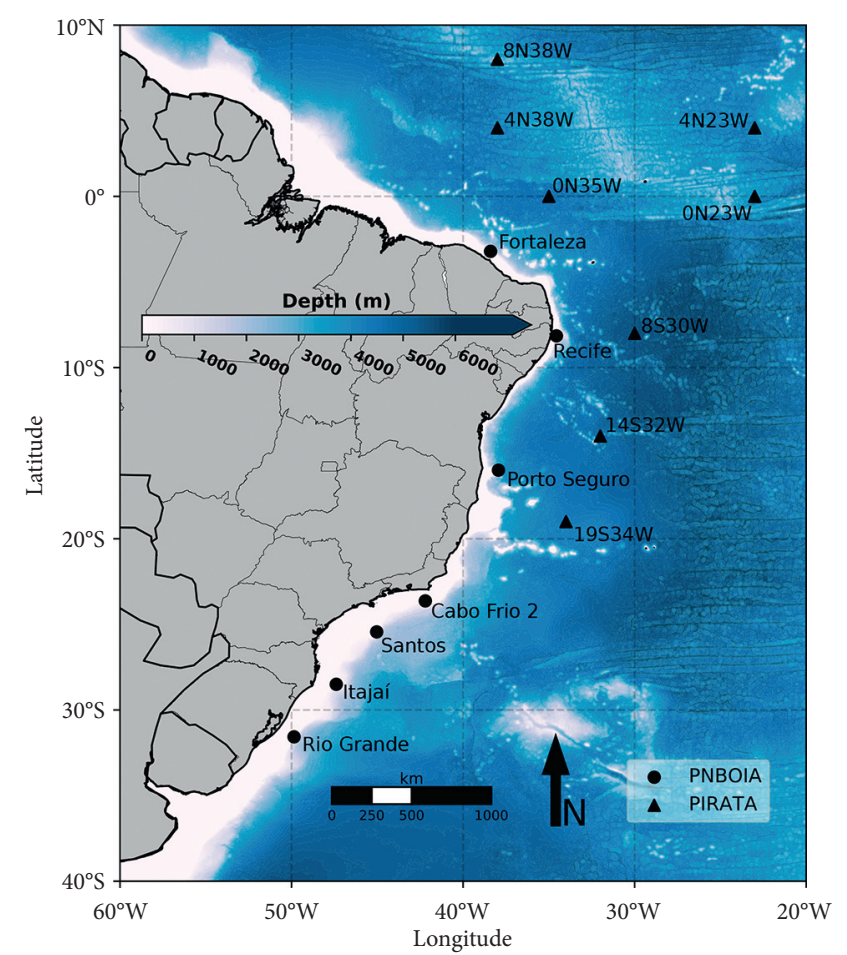

Figure 1: Map of the study area between $10^{\circ} \mathrm{N}$ and $40^{\circ} \mathrm{S}$ and between $20^{\circ} \mathrm{W}$ and $60^{\circ} \mathrm{W}$, showing the geographical locations of the 15 buoys used for in situ measurements of wind speed and direction. Symbols denote different organizational affiliations and domains: circle, Brazilian National Buoy Program (PNBOIA), shelf waters; triangle, Prediction and Research Moored Array in the Tropical Atlantic (PIRATA), oceanic waters.

which in turn is calculated from an iterative process using the wind speed measured by the buoys. For more details, please refer to References $[57,58]$.

2.2. Scatterometer Wind Data. Ocean surface wind data estimated by orbital scatterometers are derived from the ASCAT sensor, installed on board MetOp-A and MetOp-B satellites. Both satellites have been in operation since 10/2006 and $09 / 2012$, respectively, until the present. MetOp-C data were not used due to the lack of concomitant buoy data during the development of this study. Wind data were obtained from the EUMETSAT Ocean and Sea Ice Satellite Application Facility (OSI SAF) through the Royal Netherlands Meteorological Institute (KNMI). Three ASCAT products were acquired for this study: (i) ASCAT-A at processing level 2 (L2), with $12.5 \mathrm{~km}$ of spatial resolution, from the period 08/2010 to 10/2018 (https://projects.knmi.nl/ scatterometer/ascat_osi_co_prod/ascat_app.cgi); (ii) ASCAT$\mathrm{B}$, at $\mathrm{L} 2$ processing level, spatial resolution of $12.5 \mathrm{~km}$, from the period 10/2012 to 10/2018 (https://projects.knmi.nl/ scatterometer/ascat_b_osi_co_prod/ascat_app.cgi); and (iii) ASCAT Coastal Wind Data Record (ASCAT-CDR), L2 processing level, $12.5 \mathrm{~km}$ spatial resolution, from the period 01/2007 to 03/2014 (https://projects.knmi.nl/scatterometer/ ascat_cdr/). 
TABLE 1: Main characteristics of in situ measurement buoys.

\begin{tabular}{|c|c|c|c|c|c|}
\hline Dataset & Buoy & Location & Distance to the coast $(\mathrm{km})$ & \multicolumn{2}{|c|}{ Time coverage } \\
\hline \multirow{8}{*}{ PIRATA (OW) } & $8 \mathrm{~N} 38^{\circ} \mathrm{W}$ & $8^{\circ} \mathrm{N} ; 38^{\circ} \mathrm{W}$ & 1219 & 1998-01 & 2014-11 \\
\hline & $4 \mathrm{~N} 23^{\circ} \mathrm{W}$ & $4^{\circ} \mathrm{N} ; 23^{\circ} \mathrm{W}$ & 1082 & 2006-06 & 2017-03 \\
\hline & $4 \mathrm{~N} 38^{\circ} \mathrm{W}$ & $4^{\circ} \mathrm{N} ; 38^{\circ} \mathrm{W}$ & 788 & $2000-03$ & 2013-10 \\
\hline & $0 \mathrm{~N} 23^{\circ} \mathrm{W}$ & $0^{\circ} \mathrm{N} ; 23^{\circ} \mathrm{W}$ & 1491 & 1999-03 & 2016-03 \\
\hline & $0 \mathrm{~N} 35^{\circ} \mathrm{W}$ & $0^{\circ} \mathrm{N} ; 35^{\circ} \mathrm{W}$ & 563 & 1998-01 & 2015-10 \\
\hline & $8 \mathrm{~S} 30^{\circ} \mathrm{W}$ & $8^{\circ} \mathrm{S} ; 30^{\circ} \mathrm{W}$ & 531 & 2005-08 & 2015-12 \\
\hline & $14 \mathrm{~S} 32^{\circ} \mathrm{W}$ & $14^{\circ} \mathrm{S} ; 32^{\circ} \mathrm{W}$ & 614 & $2005-08$ & 2016-01 \\
\hline & $19 \mathrm{~S} 34^{\circ} \mathrm{W}$ & $19^{\circ} \mathrm{S} ; 34^{\circ} \mathrm{W}$ & 562 & 2005-09 & 2014-08 \\
\hline \multirow{7}{*}{ PNBOIA (SW) } & Fortaleza & $3.21^{\circ} \mathrm{S} ; 38.40^{\circ} \mathrm{W}$ & 54 & $2016-11$ & $2017-12$ \\
\hline & Recife & $8.15^{\circ} \mathrm{S} ; 34.56^{\circ} \mathrm{W}$ & 35 & 2012-09 & 2016-04 \\
\hline & Porto Seguro & $15.99^{\circ} \mathrm{S} ; 37.94^{\circ} \mathrm{W}$ & 99 & $2012-07$ & 2016-12 \\
\hline & Cabo Frio 2 & $23.63^{\circ} \mathrm{S} ; 42.20^{\circ} \mathrm{W}$ & 72 & 2016-07 & 2017-07 \\
\hline & Santos & $25.44^{\circ} \mathrm{S} ; 45.04^{\circ} \mathrm{W}$ & 165 & 2011-04 & 2017-08 \\
\hline & Itajaí & $28.50^{\circ} \mathrm{S} ; 47.39^{\circ} \mathrm{W}$ & 125 & 2009-04 & 2018-11 \\
\hline & Rio Grande & $31.57^{\circ} \mathrm{S} ; 49.86^{\circ} \mathrm{W}$ & 101 & 2009-04 & 2017-01 \\
\hline
\end{tabular}

OW: oceanic waters; SW: shelf waters.

The ASCAT-A and ASCAT-B products were processed using the CMOD-5n geophysical model function [59] until September 2018. From then on, the GMF CMOD-7 function [60] started to be used (Verhoef, personal communication). The ASCAT-CDR product is the result of reprocessing ASCAT-A data using the latest GMF CMOD-7. The three products, regardless of the GMF used, are optimized for coastal regions $[23,61,62]$, containing wind data at $10 \mathrm{~m}$ above sea level in along-track grids (along the satellite path) with a spatial resolution of $12.5 \mathrm{~km}$, coming from 14 orbital cycles per day.

Table 2 summarizes the main characteristics of all alternative offshore wind products used in this study.

2.3. BRAMS Numerical Forecasting Model. The Brazilian Regional Atmospheric Modelling System (BRAMS) is a numerical simulation system designed for atmospheric forecasting and research from regional to hemispheric scales. Based on the Regional Atmospheric Modelling System (RAMS), originally developed at Colorado State University, BRAMS was until recently developed and maintained by the Centre for Weather Forecasting and Climate Studies (CPTEC) of the Brazilian National Institute for Space Research (INPE), the University of São Paulo, and other institutions in Brazil and abroad. The computational code of BRAMS is free software with General Public License (CC-GPL). More information about BRAMS can be found at http://brams.cptec.inpe.br/. BRAMS simulations for 2013-2015 were provided by CPTEC/INPE, containing wind data at $10 \mathrm{~m}$ in grids with $5 \mathrm{~km}$ of spatial resolution and hourly temporal resolution. The coverage area is between $7.6^{\circ} \mathrm{N}-37.3^{\circ} \mathrm{S}$ and $62.5^{\circ} \mathrm{W}-29.6^{\circ} \mathrm{W}$.

2.4. Blended CCMP Data. The Cross-Calibrated MultiPlatform (CCMP) is a level 3 (L3) wind product which uses satellite and in situ data, and numerical modelling simulations. The first CCMP version, described in the study of Atlas et al. [63], was discontinued in 2012. The second CCMP version used in this work is described in the study of
Wentz et al. [64]. This dataset uses the variational analysis method (VAM) to fill gaps in the gridded product [65-67]. VAM generates a surface wind grid, minimizing an objective function, which measures the mismatch of the in situ and satellite wind data overlaid on reanalysis bottom base, considered as an initial estimate [63]. Wind data at $10 \mathrm{~m}$ from the CCMP product are available in regular grids for dates after 1987 with a spatial resolution of $25 \mathrm{~km}$ and a temporal resolution of six hours. Data were obtained for the period from 01/1998 to 12/2018 (http://www.remss.com/ measurements/ccmp/).

2.5. ERA5 Reanalysis. The ERA5 Reanalysis product is developed by the Copernicus Climate Change Service, implemented by the European Centre for Medium-Range Weather Forecasts (ECMWF) (https://www.ecmwf.int/en/ forecasts/datasets/archive-datasets/reanalysis-datasets/ era5). Reanalysis data are produced by combining shortterm numerical predictions with observational data. ERA5 is produced using the assimilation of atmosphere and surface data in four dimensions through the ECMWF Integrated Forecast System with 137 vertical levels in sigma coordinates (which use atmospheric pressure on the surface as a reference) in grids with $31 \mathrm{~km}$ of resolution for atmospheric levels. Hourly ERA5 data are available for several atmospheric variables, including wind zonal and meridional components, and air temperature at $10 \mathrm{~m}$ above sea level. Monthly updates of ERA5 hourly data on single levels from 1979 to present are published within 3 months of real time. Data were obtained for the period from $01 / 2000$ to $12 / 2017$.

2.6. Statistical Analysis. To compare the different sources of offshore wind speed data with the in situ buoy measurements, the root mean square error $\left(\mathrm{RMSE}_{\mathrm{spd}}\right)$, bias spd, , Pierson correlation coefficient $\left(R_{\mathrm{spd}}\right)$, and standard deviation $\left(\sigma_{\text {spd }}\right)$ were calculated considering the simultaneous and valid wind speed data records among all datasets, according to the following equations: 
TABLe 2: Main characteristics of the considered wind products.

\begin{tabular}{|c|c|c|c|c|c|c|}
\hline $\begin{array}{l}\text { Wind } \\
\text { product }\end{array}$ & $\begin{array}{l}\text { Type of } \\
\text { dataset }\end{array}$ & Included data sources & $\begin{array}{c}\text { Processing } \\
\text { level }\end{array}$ & $\begin{array}{c}\text { Spatial } \\
\text { resolution }\end{array}$ & $\begin{array}{l}\text { Temporal } \\
\text { resolution }\end{array}$ & $\begin{array}{c}\text { Time } \\
\text { coverage }\end{array}$ \\
\hline $\begin{array}{l}\text { ASCAT-A } \\
\text { Coastal }\end{array}$ & Satellite & ASCAT/MetOP-A & $\mathrm{L} 2 \mathrm{~B}$ & $12.5 \mathrm{~km}$ & $\begin{array}{l}3-5 \text { swaths/ } \\
\text { day }\end{array}$ & 2007-present \\
\hline $\begin{array}{l}\text { ASCAT-B } \\
\text { Coastal }\end{array}$ & Satellite & ASCAT/MetOP-B & L2B & $12.5 \mathrm{~km}$ & $\begin{array}{l}3-5 \text { swaths/ } \\
\text { day }\end{array}$ & 2012-present \\
\hline $\begin{array}{l}\text { ASCAT- } \\
\text { CDR }\end{array}$ & Satellite & ASCAT/MetOP-A & $\mathrm{L} 2 \mathrm{~B}$ & $12.5 \mathrm{~km}$ & $\begin{array}{l}3-5 \text { swaths/ } \\
\text { day }\end{array}$ & $2007-2014$ \\
\hline BRAMS & NWP & $\begin{array}{c}\text { Forcing data from reanalysis } \\
\text { ECMWF analyses, QuikSCAT, ASCAT/ }\end{array}$ & - & $5 \mathrm{~km}$ & Hourly & 2013-2015 \\
\hline CCMP V2.0 & Blended & $\begin{array}{c}\text { MetOP-A, WindSat, SSM/I, SSMIS, AMSR-E, } \\
\text { AMSR2, GMI }\end{array}$ & L3 & 0.25 lat/lon & 6 hours & 1987-present \\
\hline ERA5 & Reanalysis & NWP and observations & - & $31 \mathrm{~km}$ & Hourly & 1979-present \\
\hline
\end{tabular}

$$
\begin{aligned}
\mathrm{RMSE}_{\mathrm{spd}} & =\sqrt{\frac{1}{N} \sum_{i=1}^{N}\left(x_{e, i}-x_{r, i}\right)^{2},} \\
\operatorname{bias}_{\mathrm{spd}} & =\frac{1}{N} \sum_{i=1}^{N}\left(x_{e, i}-x_{r, i}\right), \\
R_{\mathrm{spd}} & =\frac{\sum_{i=1}^{N}\left(x_{e, i}-\bar{x}_{e}\right)\left(x_{r, i}-\bar{x}_{r}\right)}{\sqrt{\sum_{i=1}^{N}\left(x_{e, i}-\bar{x}_{e}\right)^{2}} \sqrt{\sum_{i=1}^{N}\left(x_{r, i}-\bar{x}_{r}\right)^{2}}}, \\
\sigma_{\mathrm{spd}} & =\sqrt{\frac{1}{N} \sum_{i=1}^{N}\left(x_{i}-\bar{x}\right)^{2},}
\end{aligned}
$$

where $x$ refers to the wind speed values at instant $i, r$ refers to the in situ buoy data used as a reference, and $e$ refers to the data estimated by the alternative sources of wind data.

Regarding wind direction data, the circular statistics was applied. The mean direction $(\bar{\theta})$ is estimated as follows:

$$
\bar{\theta}=\left\{\begin{array}{cc}
\tan ^{-1} \frac{S}{C}, & \text { if } C>0, S>0 \\
\tan ^{-1} \frac{S}{C}+180^{\circ}, & \text { if } C<0 \\
\tan ^{-1} \frac{S}{C}+360^{\circ}, & \text { if } C>0, S<0
\end{array}\right\} .
$$

Considering each angle $(\theta)$ in an instant $i$ as a vector, $C=\sum_{i=1}^{N} \cos \left(\theta_{i}\right)$ and $S=\sum_{i=1}^{N} \sin \left(\theta_{i}\right)$ are the respective $x$ and $y$-axis representations of the resultant vector length $(r)$. The circular standard deviation $\left(\sigma_{\text {dir }}\right)$ is estimated by the following equation:

$$
\sigma_{\text {dir }}=\sqrt{2 \ln (\bar{r})},
$$

where $\bar{r}=(r / N)=\left(\sqrt{C^{2}+S^{2}} / N\right)$ would be the mean resultant length. The circular correlation $\left(R_{\text {dir }}\right)$ is defined as

$$
R_{\mathrm{dir}}=\frac{\sum_{i=1}^{N} \sin \left(\theta_{r, i}-\overline{\theta_{r}}\right) \sin \left(\theta_{e, i}-\overline{\theta_{e}}\right)}{\sqrt{\sum_{i=1}^{N} \sin ^{2}\left(\theta_{r, i}-\overline{\theta_{r}}\right) \sin ^{2}\left(\theta_{e, i}-\overline{\theta_{e}}\right)}} .
$$

Please, refer to the study of Jammalamadaka and Sengupta [68] for more information about circular statistics. The bias and RMSE formulas for wind direction data are the same as for wind speed data. However, the minor angle difference $\left(\theta_{d}\right)$ was derived as follows:

$$
\theta_{d, i}=\left\{\begin{array}{cc}
\theta_{e, i}-\theta_{r, i}, & \text { if }-180^{\circ}<\left(\theta_{e, i}-\theta_{r, i}\right)<180^{\circ} \\
\theta_{e, i}-\theta_{r, i}-360, & \text { if }\left(\theta_{e, i}-\theta_{r, i}\right)>180^{\circ} \\
\theta_{e, i}-\theta_{r, i}+360, & \text { if }\left(\theta_{e, i}-\theta_{r, i}\right)<-180^{\circ}
\end{array}\right\} .
$$

Therefore, RMSE and bias for direction can be read as follows:

$$
\begin{aligned}
\mathrm{RMSE}_{\mathrm{dir}} & =\sqrt{\frac{1}{N} \sum_{i=1}^{N}\left(\theta_{d, i}\right)^{2},} \\
\text { bias }_{\mathrm{dir}} & =\frac{1}{N} \sum_{i=1}^{N}\left(\theta_{d, i}\right) .
\end{aligned}
$$

The comparisons considered the buoys geographic coordinates and the respective grid point or pixel of the other datasets. Each buoy is identified by its name (PNBOIA, shelf waters) or geographic coordinates (PIRATA, oceanic waters), as adopted by the respective monitoring programs. An interval of 30 minutes was considered around the measurement time of the in situ PNBOIA data, and of 5 minutes in the case of PIRATA buoys, according to the respective temporal resolution of the in situ data recording (hourly or 10 minutes, respectively). Two approaches were taken for data comparison, prioritizing different criteria: (i) the first approach compared data that were obtained simultaneously by all the five datasets-ASCAT, CCMP, ERA5, BRAMS, buoys-(ii) a second approach compared all available paired data separately for each buoy. When comparing 
simultaneous data (i), the Taylor diagrams [69] were produced, and ASCAT-A, ASCAT-B, and ASCAT-CDR data were considered separately, due to the difficulty of matching them over time. Wind roses diagrams were also generated.

\section{Results}

3.1. In Situ Buoy Data. Wind roses of oceanic water buoys (PIRATA) show a low variability in the wind direction, except for the buoys moored in the north-south oscillation region of the Intertropical Convergence Zone [44, 70] (Figure 2). The northernmost buoy (8N38W) has dominant $\mathrm{NE}$ winds and the buoys $4 \mathrm{~N} 23 \mathrm{~W}$ and $4 \mathrm{~N} 38 \mathrm{~W}$ have two predominant wind directions: NNE-SSE and NE-SE, respectively. These buoys also have relatively higher standard deviations in wind direction $\left(52.6^{\circ}\right.$ and $82.1^{\circ}$, Table 3$)$. The $0 \mathrm{~N} 35 \mathrm{~W}$ and $08 \mathrm{~S} 30 \mathrm{~W}$ buoys have dominant winds from ESE and the 0N23W buoy from SE. Buoys 14S32W and 19S34W have dominant E-SE and E-NE winds, respectively. The higher mean wind speeds were observed for buoys $8 \mathrm{~S} 30 \mathrm{~W}$ $\left(7.36 \mathrm{~m} \cdot \mathrm{s}^{-1}\right)$ and $14 \mathrm{~S} 32 \mathrm{~W}\left(6.92 \mathrm{~m} \cdot \mathrm{s}^{-1}\right)$.

For shelf water buoys PNBOIA, the higher mean wind speeds were observed in Fortaleza $\left(8.91 \mathrm{~m} \cdot \mathrm{s}^{-1}\right)$, Rio Grande $\left(8.34 \mathrm{~m} \cdot \mathrm{s}^{-1}\right)$, Itajaí $\left(7.68 \mathrm{~m} \cdot \mathrm{s}^{-1}\right)$, and Cabo Frio $2\left(7.52 \mathrm{~m} \cdot \mathrm{s}^{-1}\right)$ (Figure 2, Table 3). Fortaleza, Recife, and Cabo Frio 2 buoys showed a lower variability in wind direction, with dominance from the SE-E and NE quadrants, respectively. However, in Cabo Frio 2, the standard deviation of the mean wind direction was $75.0^{\circ}$ (Table 3 ), while for Fortaleza and Recife, the standard deviations were lower $\left(23.1^{\circ}\right.$ and $33.3^{\circ}$, respectively).

3.2. Ocean Surface Wind Statistical Comparisons. Throughout the statistical comparisons presented below, a negative systematic bias was observed for the BRAMS wind speed data, which was corrected by applying the scaled distribution mapping method [71]. For oceanic waters (OW) buoys comparisons, the correction of the systematic bias resulted in lower $\mathrm{RMSE}_{\text {spd }}$ values (a decrease of $1.8 \mathrm{~m} \cdot \mathrm{s}^{-1}$ in the best case), while for shelf waters (SW) buoys, there was no relevant change with slightly higher $\mathrm{RMSE}_{\text {spd }}$ values for two buoys (Figure S1 in Supplemental File). Therefore, BRAMS wind speed data with systematic bias correction were used only for comparisons with OW buoys.

The simultaneous comparisons of the ocean surface wind products with in situ measured buoys data did not differ much with respect to wind speed (Figures 3-5 and Table S1 in Supplemental File). Considering the comparison of all buoys together, the $\mathrm{RMSE}_{\mathrm{spd}}$ values ranged between $0.98 \mathrm{~m} \cdot \mathrm{s}^{-1}$ and $1.82 \mathrm{~m} \cdot \mathrm{s}^{-1}$. Considering the $\mathrm{OW}$ and $\mathrm{SW}$ buoys separately, the RMSE $\mathrm{spd}_{\text {salues were relatively lower }}$ $\left(0.91 \mathrm{~m} \cdot \mathrm{s}^{-1}\right.$ and $1.02 \mathrm{~m} \cdot \mathrm{s}^{-1}$ in the best cases, respectively). The highest values of $\mathrm{RMSE}_{\text {spd }}$ were obtained for the product BRAMS, even after removing the systematic bias. For all

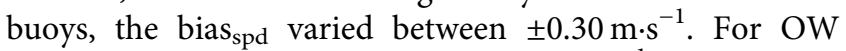
buoys, the bias spd varied between $\pm 0.19 \mathrm{~m} \cdot \mathrm{s}^{-1}$. For SW, the bias $_{\text {spd }}$ varied between $-0.18 \mathrm{~m} \cdot \mathrm{s}^{-1}$ and $-0.25 \mathrm{~m} \cdot \mathrm{s}^{-1}$ for ASCAT and CCMP products and between $-0.70 \mathrm{~m} \cdot \mathrm{s}^{-1}$ and
$-0.48 \mathrm{~m} \cdot \mathrm{s}^{-1}$ for BRAMS and ERA5. The highest correlations $\left(R_{\mathrm{spd}}>0.87\right)$ were obtained for ASCAT products considering all and SW buoys, or CCMP considering OW buoys.

In general, relatively higher differences were observed in relation to wind direction, especially for shelf water buoys. Best results were obtained for OW with $\mathrm{RMSE}_{\text {dir }}$ values $<23.2^{\circ}$, bias dir $_{\text {between }}-0.09^{\circ}$ and $0.19^{\circ}$, and correlations $>0.83$, except for the BRAMS product $\left(\mathrm{RMSE}_{\mathrm{dir}}=31.2^{\circ}\right.$, bias $_{\mathrm{dir}}=-1.40^{\circ}, R_{\mathrm{dir}}=0.72$, in the best cases). Considering all buoys, the values of RMSE $\mathrm{dir}_{\text {and }}$ and bias $_{\text {dir }}$ varied between $46.8^{\circ}$ and $53.4^{\circ}$, and between $-1.06^{\circ}$ and $4.88^{\circ}$, respectively. Also, the best correlations $\left(R_{\mathrm{dir}}>0.87\right)$ were obtained for the CCMP product. On the contrary, high $\mathrm{RMSE}_{\text {dir }}$ values $>73.5^{\circ}$, bias dir $_{\text {between }}-14.34^{\circ}$ and $-0.09^{\circ}$ and lower correlations $(<0.35)$ were obtained for SW.

The comparisons of all available paired data for each oceanic water buoy did not differ much with respect to wind speed (Figure 6 and Table S2 in Supplemental File). The

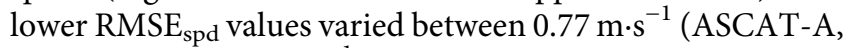
$0 \mathrm{~N} 23 \mathrm{~W}$ ) and $1.13 \mathrm{~m} \cdot \mathrm{s}^{-1}$ (ASCAT-B, 19S34W), except for BRAMS $\left(1.04 \mathrm{~m} \cdot \mathrm{s}^{-1}\right.$ to $\left.1.90 \mathrm{~m} \cdot \mathrm{s}^{-1}\right)$, with bias $_{\text {spd }}$ between $-0.73 \mathrm{~m} \cdot \mathrm{s}^{-1}$ (ERA5, 4N23W) and $0.43 \mathrm{~m} \cdot \mathrm{s}^{-1}$ (ASCAT-B, $8 \mathrm{~N} 38 \mathrm{~W}$ ), and correlation coefficients between 0.61 (BRAMS, $4 \mathrm{~N} 38 \mathrm{~W}$ ) and 0.92 (ASCAT-A, 8N38W). Regarding wind direction, the lower $\mathrm{RMSE}_{\mathrm{dir}}$ values varied between $13.7^{\circ}$ (CCMP, 8S30W) and $32.5^{\circ}$ (ASCAT-B and ASCAT-CDR, 4N23W), with bias $_{\text {dir }}$ between $-9.18^{\circ}$ (ASCAT-A, 4N38W) and $19.5^{\circ}$ (BRAMS, 19S34W), and correlation coefficients between 0.57 (BRAMS, 0N35W) and 0.92 (CCMP, 4N38W). In general, the lower RMSE and bias values and the higher $R$ values, both for wind speed and direction, were obtained for the ASCAT and CCMP products.

The comparisons of all available paired data for each shelf water buoy did not differ much with respect to wind speed (Figure 7 and Table S3 in Supplemental File). The

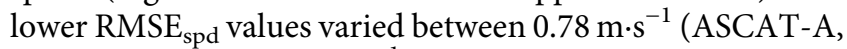
Cabo Frio 2) and $1.09 \mathrm{~m} \cdot \mathrm{s}^{-1}$ (ASCAT-B, Itajaí), with bias spd $_{\text {s. }}$ between $-1.21 \mathrm{~m} \cdot \mathrm{s}^{-1}$ (ERA5, Fortaleza) and $-0.004 \mathrm{~m} \cdot \mathrm{s}^{-1}$ (ASCAT-B, Rio Grande), and $R_{\text {spd }}$ between 0.51 (BRAMS, Recife) and 0.96 (ASCAT-A, Fortaleza, and ASCAT-B, Cabo Frio 2). Regarding wind direction, the lower $\mathrm{RMSE}_{\mathrm{dir}}$ values varied between $12.7^{\circ}$ (ASCAT-B, Fortaleza) and $79.6^{\circ}$ (CCMP, Santos), with bias ${ }_{\text {dir }}$ between $-28.5^{\circ}$ (BRAMS, Santos) and $40.5^{\circ}$ (BRAMS, Rio Grande), and circular correlation coefficients between 0.58 (CCMP and ERA5, Itajaí) and 0.94 (ASCAT-B, Fortaleza), except for comparisons with the Santos buoy $(\leq 0.34)$.

3.3. Error Dependence on Measured Wind Speed. Scatterometers limitations in representing low and high wind speeds are well documented in the literature [72, 73]. To analyze if wind speeds from the alternative wind data sources show any variation or dependence with the in situ buoy data, four different bins were considered for statistical comparison: $3-6 \mathrm{~m} \cdot \mathrm{s}^{-1} ; 6-9 \mathrm{~m} \cdot \mathrm{s}^{-1} ; 9-12 \mathrm{~m} \cdot \mathrm{s}^{-1}$ and $>12 \mathrm{~m} \cdot \mathrm{s}^{-1}$ (Figures 8 and 9 and Table S4 in Supplemental File). In general, the lowest $\mathrm{RMSE}_{\mathrm{spd}}\left(0.76 \mathrm{~m} \cdot \mathrm{s}^{-1}\right)$ and bias ${ }_{\text {spd }}$ $\left(-0.05 \mathrm{~m} \cdot \mathrm{s}^{-1}\right)$, and highest $R_{\text {spd }}$ values $(0.70)$ were observed 

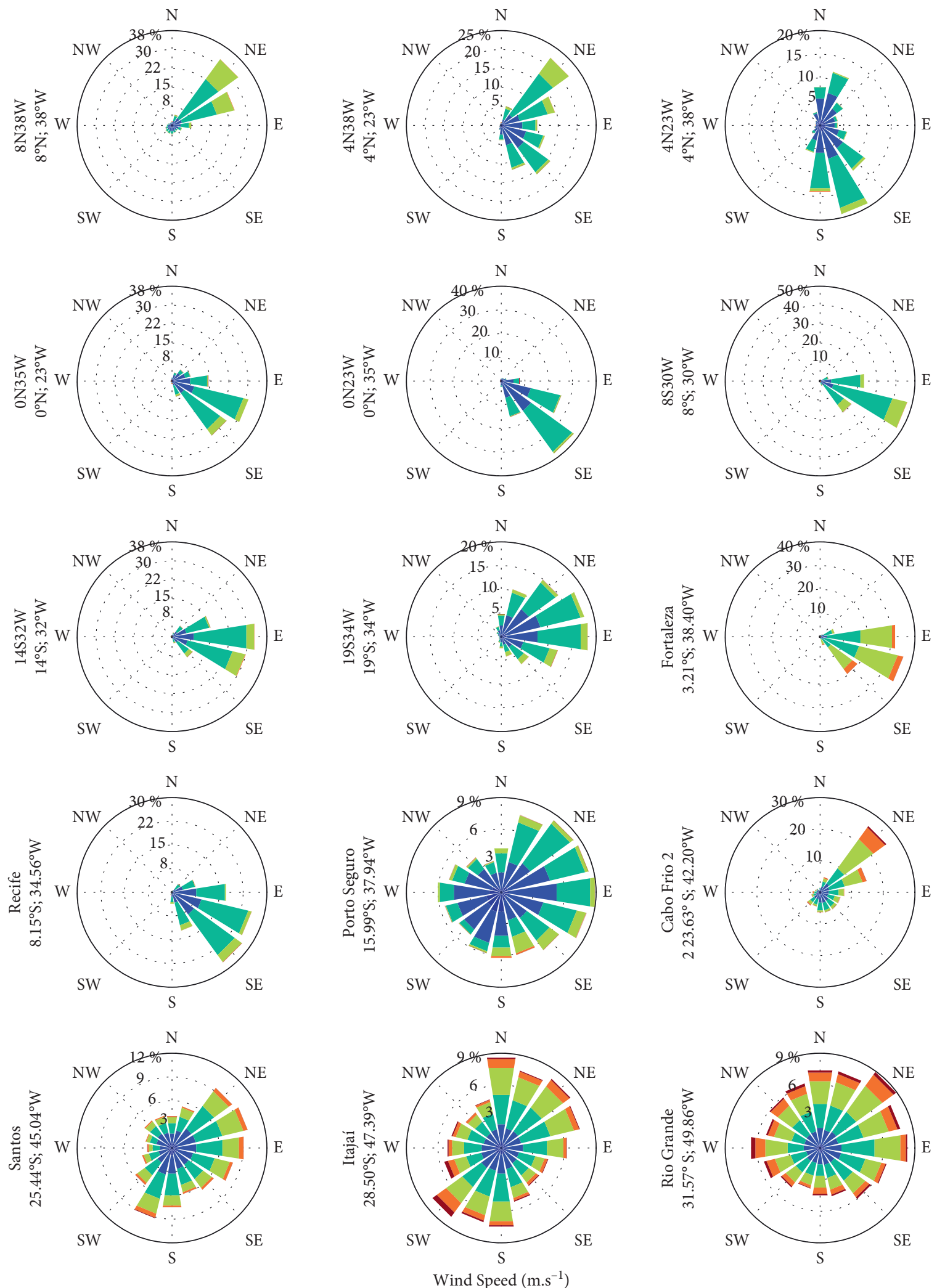

$\begin{array}{lll}\square-3 & \square-9 \\ 3-6 & \square-12 & \square-15 \\ 9 & \square\end{array}$

Figure 2: Wind roses of oceanic (PIRATA) and shelf (PNBOIA) water buoys. 
TABLE 3: Mean ( \pm standard deviation) and maximum and minimum wind speed and circular mean ( \pm circular standard deviation) wind direction from the in situ measurement buoys.

\begin{tabular}{|c|c|c|c|c|c|}
\hline \multirow{2}{*}{ Dataset } & \multirow{2}{*}{ Buoy } & \multicolumn{2}{|c|}{ Mean } & \multirow{2}{*}{$\begin{array}{c}\text { Max } \\
\text { Speed }\left(\mathrm{ms}^{-1}\right)\end{array}$} & \multirow{2}{*}{$\begin{array}{c}\text { Min } \\
\text { Speed }\left(\mathrm{ms}^{-1}\right)\end{array}$} \\
\hline & & Speed $\left(\mathrm{ms}^{-1}\right)$ & Dir. $\left({ }^{\circ}\right)$ & & \\
\hline \multirow{8}{*}{ PIRATA (OW) } & $8 \mathrm{~N} 38 \mathrm{~W}$ & $6.78 \pm 2.60$ & $244 \pm 60.0$ & 20.6 & 0.00 \\
\hline & $4 \mathrm{~N} 23 \mathrm{~W}$ & $5.38 \pm 2.17$ & $307 \pm 82.1$ & 32.3 & 0.00 \\
\hline & $4 \mathrm{~N} 38 \mathrm{~W}$ & $6.31 \pm 2.21$ & $274 \pm 52.6$ & 17.9 & 0.00 \\
\hline & 0N23W & $5.67 \pm 1.89$ & $306 \pm 35.5$ & 19.0 & 0.00 \\
\hline & 0N35W & $6.27 \pm 2.07$ & $288 \pm 38.2$ & 17.1 & 0.00 \\
\hline & $8 \mathrm{~S} 30 \mathrm{~W}$ & $7.36 \pm 1.70$ & $290 \pm 20.5$ & 16.3 & 0.00 \\
\hline & $14 \mathrm{~S} 32 \mathrm{~W}$ & $6.92 \pm 1.90$ & $276 \pm 28.1$ & 17.1 & 0.00 \\
\hline & $19 \mathrm{~S} 34 \mathrm{~W}$ & $6.15 \pm 2.17$ & $254 \pm 52.3$ & 16.5 & 0.00 \\
\hline \multirow{7}{*}{ PNBOIA (SW) } & Fortaleza & $8.91 \pm 2.19$ & $287 \pm 23.1$ & 16.0 & 0.43 \\
\hline & Recife & $6.53 \pm 1.76$ & $298 \pm 33.3$ & 47.4 & 0.11 \\
\hline & Porto Seguro & $5.53 \pm 2.42$ & $280 \pm 111$ & 16.1 & 0.11 \\
\hline & Cabo Frio 2 & $7.52 \pm 3.19$ & $264 \pm 75.0$ & 16.3 & 0.11 \\
\hline & Santos & $6.88 \pm 3.07$ & $290 \pm 102$ & 20.1 & 0.11 \\
\hline & Itajaí & $7.68 \pm 3.41$ & $242 \pm 146$ & 36.3 & 0.11 \\
\hline & Rio Grande & $8.34 \pm 3.58$ & $218 \pm 113$ & 48.9 & 0.11 \\
\hline
\end{tabular}

OW: oceanic waters; SW: shelf waters.

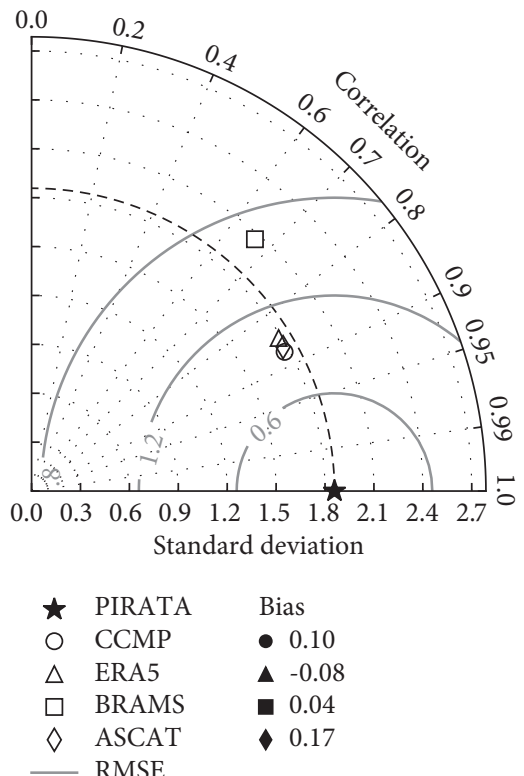

(a)

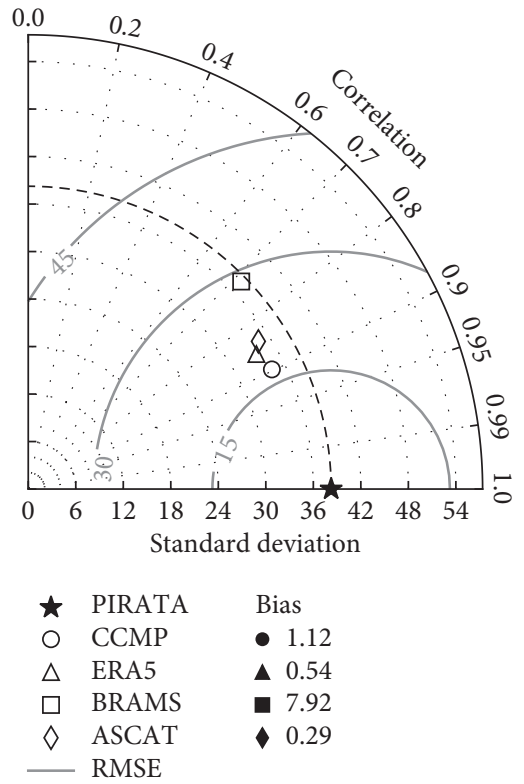

(b)
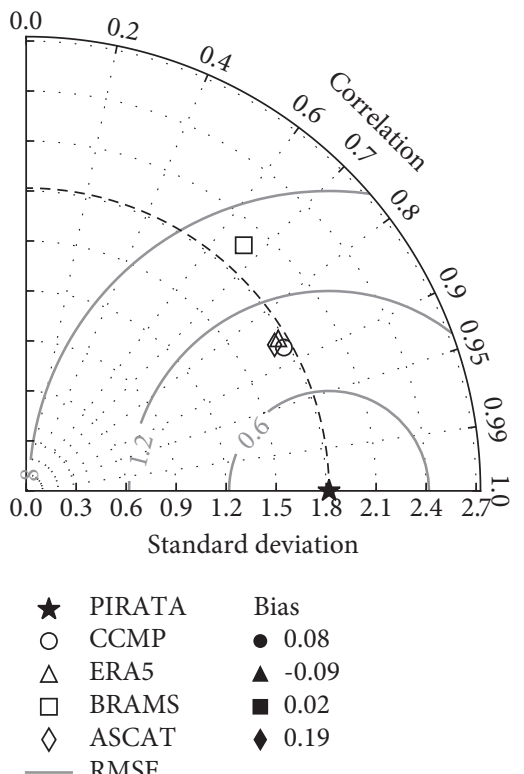

(c)

Figure 3: Continued. 


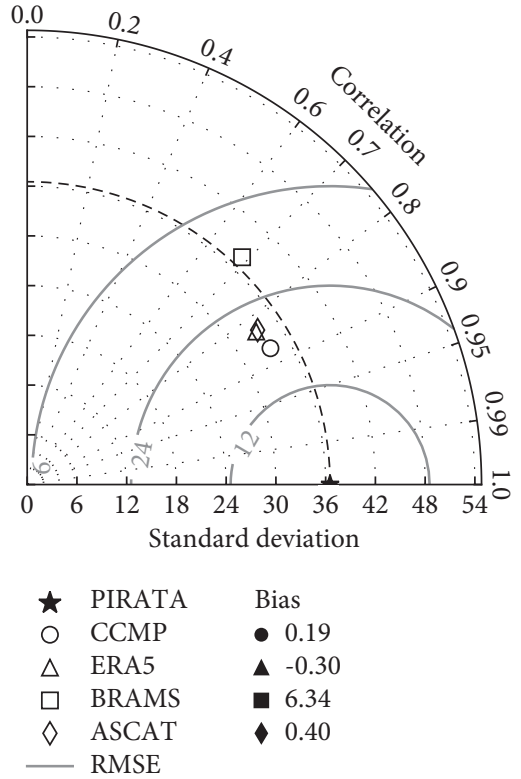

(d)

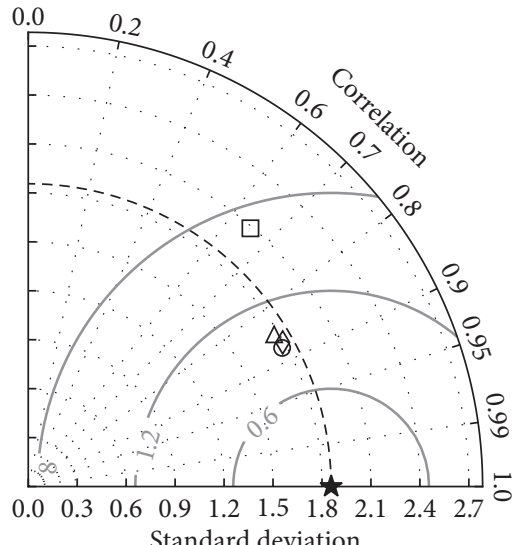

Standard deviation

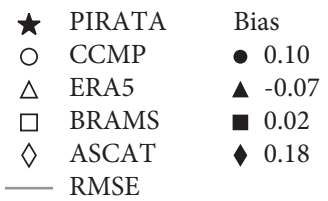

(e)
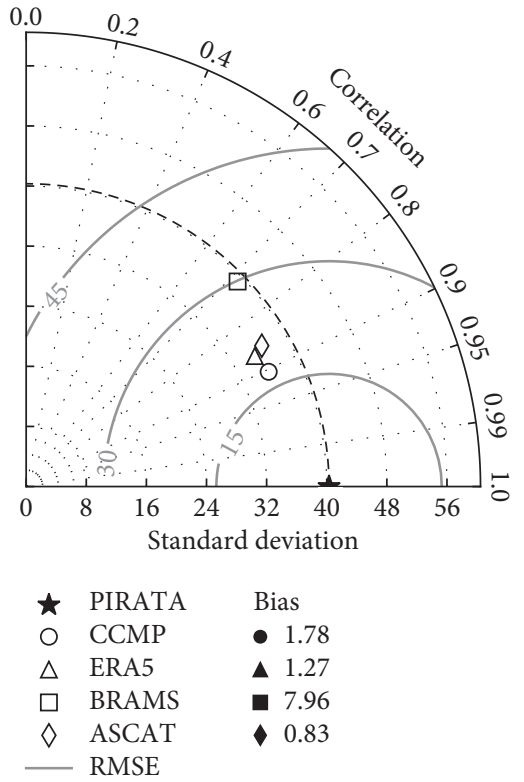

(f)

FIGURE 3: Taylor diagrams for statistical comparisons between CCMP, BRAMS, ERA5, and ASCAT-A (a, b), or ASCAT-B (c, d), or ASCAT$\operatorname{CDR}(e, f)$ that have coincident records with oceanic water buoy data. (a) Speed-ASCAT-A. (b) Direction-ASCAT-A. (c) Speed-ASCAT-B. (d) Direction-ASCAT-B. (e) Speed-ASCAT-CDR. (f) Direction-ASCAT-CDR.

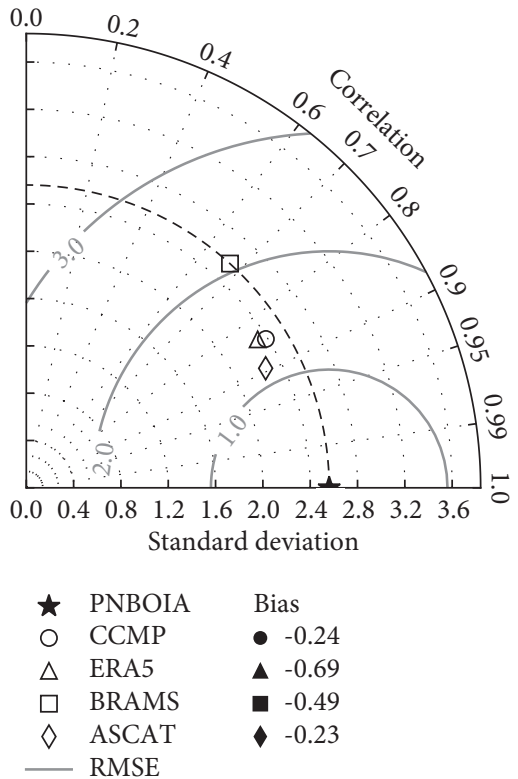

(a)
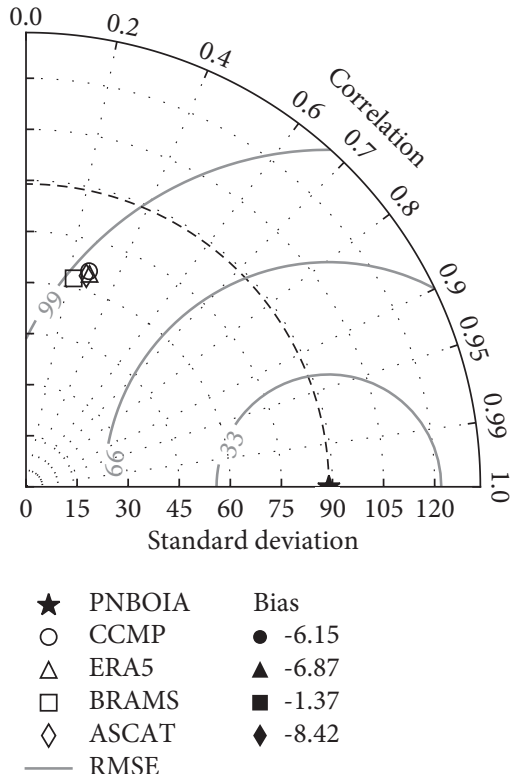

(b)

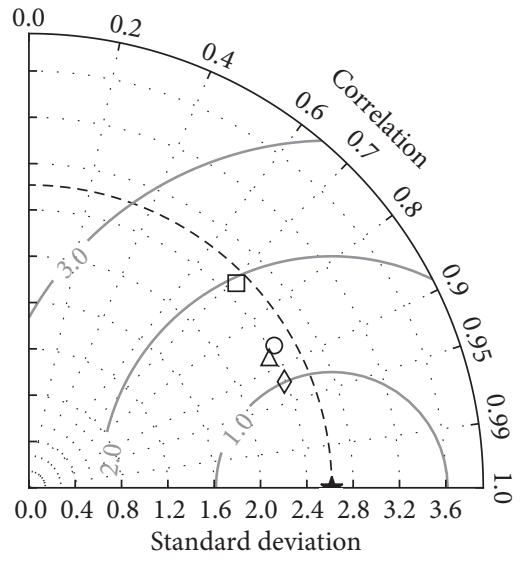

$\begin{array}{lll}\star & \text { PNBOIA } & \text { Bias } \\ \bigcirc & \text { CCMP } & \bullet-0.25 \\ \triangle & \text { ERA5 } & \boldsymbol{\Delta}-0.70 \\ \square & \text { BRAMS } & -0.60 \\ \diamond & \text { ASCAT } & -0.18 \\ & \text { RMSE } & \end{array}$

(c)

Figure 4: Continued. 


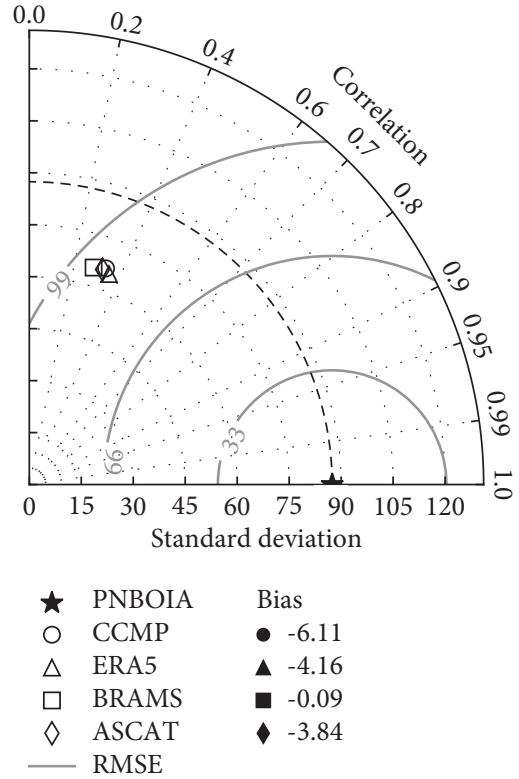

(d)

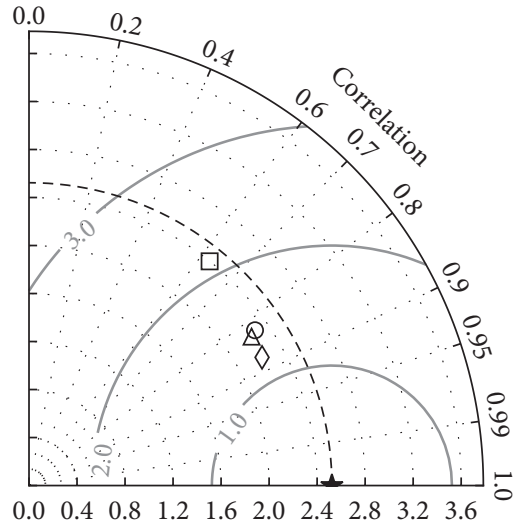

Standard deviation

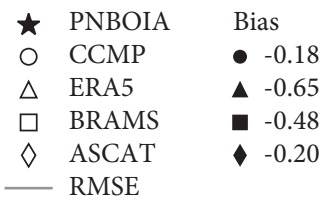

(e)
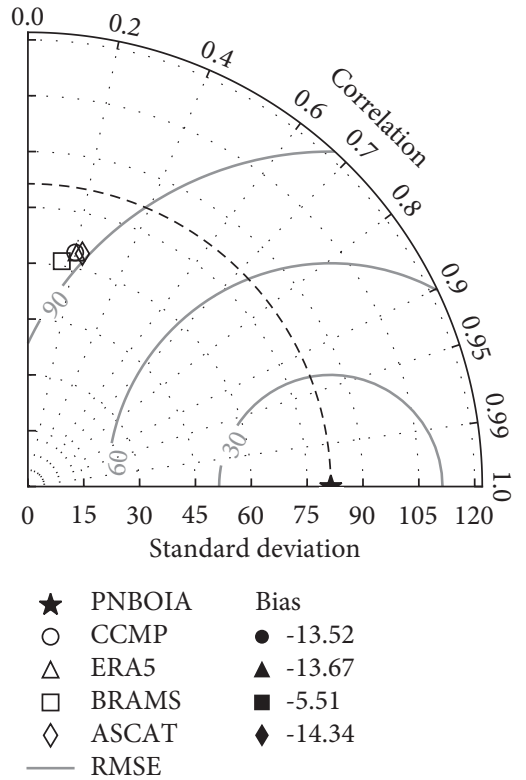

(f)

FIGURE 4: Taylor diagrams for statistical comparisons between CCMP, BRAMS, ERA5, and ASCAT-A (a, b), or ASCAT-B (c, d), or ASCAT$\operatorname{CDR}(e, f)$ that have coincident records with shelf water buoy data. (a) Speed-ASCAT-A. (b) Direction-ASCAT-A. (c) Speed-ASCAT-B. (d) Direction-ASCAT-B. (e) Speed-ASCAT-CDR. (f) Direction-ASCAT-CDR.

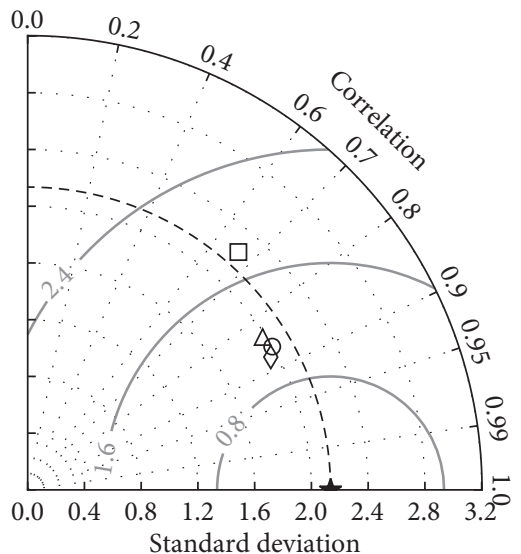

Standard deviation

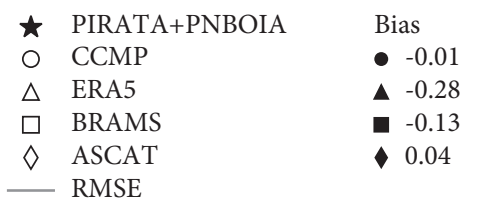

(a)
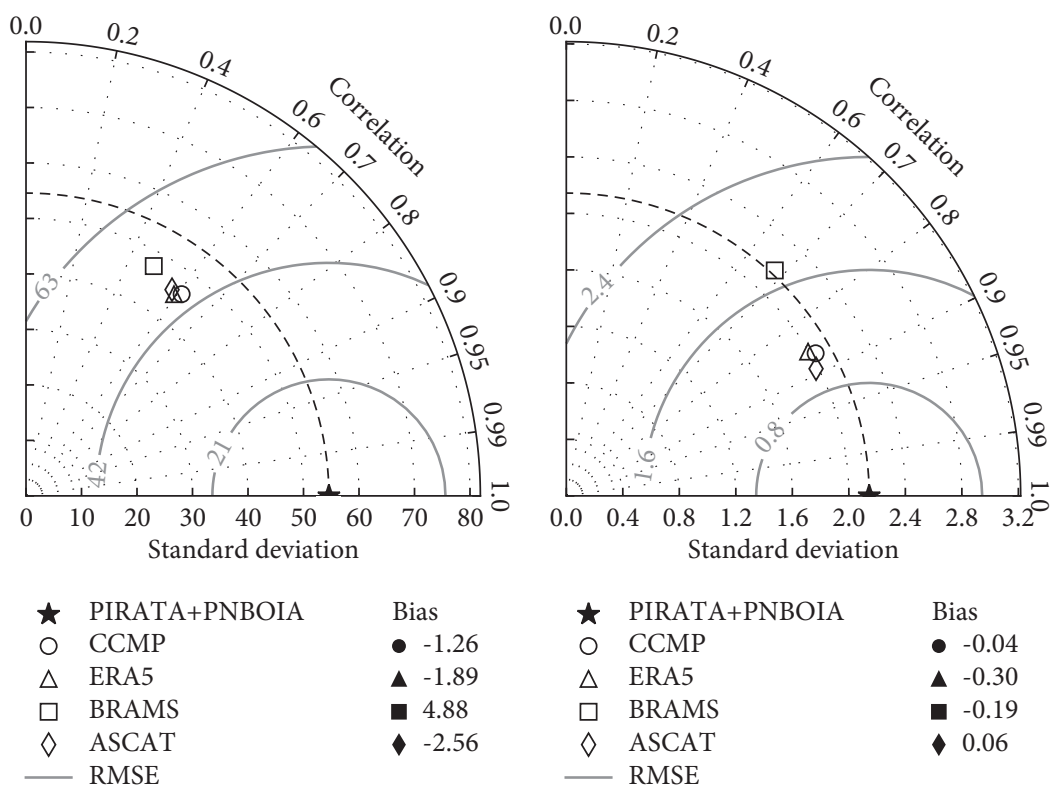

(b)

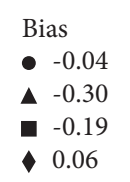

(c)

FIGURE 5: Continued. 

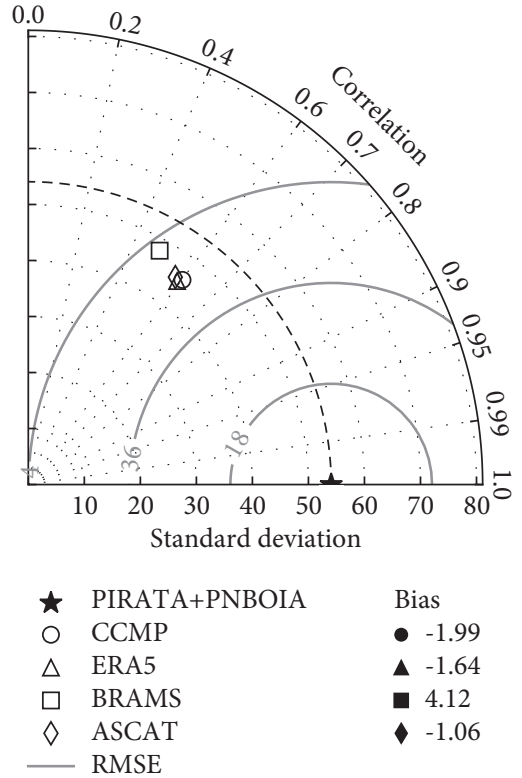

(d)

$$
\begin{aligned}
& \text { Bias } \\
& \text { - }-1.99 \\
& \text { А }-1.64 \\
& \text { - } 4.12 \\
& \text { - }-1.06
\end{aligned}
$$

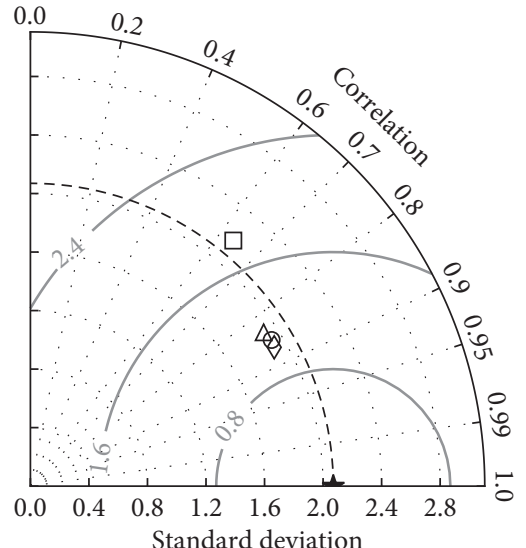

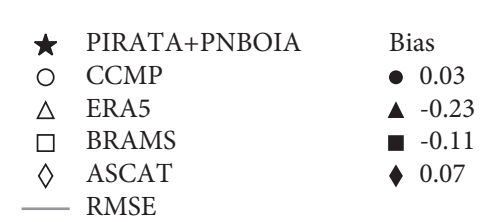

(e)
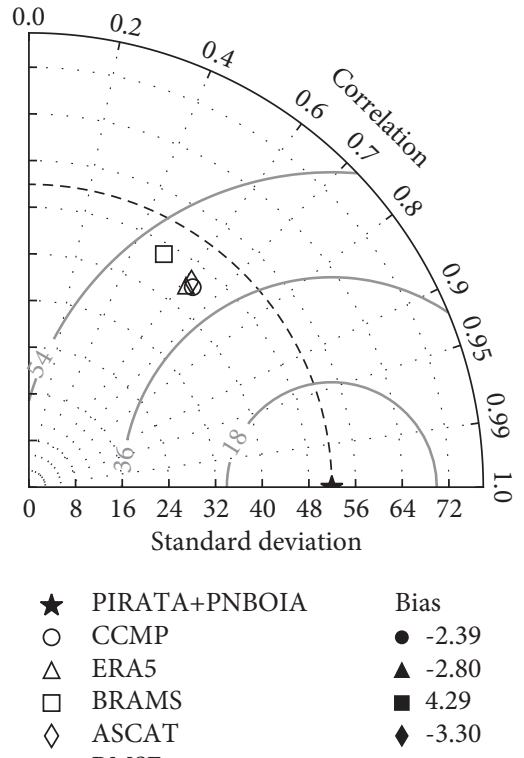

(f)

FIgURE 5: Taylor diagrams for statistical comparisons between CCMP, BRAMS, ERA5, and ASCAT-A (a, b), or ASCAT-B (c, d), or ASCAT$\operatorname{CDR}(e, f)$ that have coincident records with all buoys data. (a) Speed-ASCAT-A. (b) Direction-ASCAT-A. (c) Speed-ASCAT-B. (d) Direction-ASCAT-B. (e) Speed-ASCAT-CDR. (f) Direction-ASCAT-CDR.

in the $6-9 \mathrm{~m} \cdot \mathrm{s}^{-1}$ interval, while higher differences were observed for winds $>12 \mathrm{~m} \cdot \mathrm{s}^{-1}\left(1.11 \mathrm{~m} \cdot \mathrm{s}^{-1}<\mathrm{RMSE}_{\mathrm{spd}}\right.$ $>4.59 \mathrm{~m} \cdot \mathrm{s}^{-1},-3.55 \mathrm{~m} \cdot \mathrm{s}^{-1}<$ bias $\left._{\text {spd }}>-0.59 \mathrm{~m} \cdot \mathrm{s}^{-1}\right)$. For all speed intervals and all datasets considered in the analysis, the lower RMSE $E_{\text {spd }}$ values and higher $R_{\text {spd }}$ values were obtained for ASCAT-A and ASCAT-B products. Regarding wind direction, higher differences were observed in the $3-6 \mathrm{~m} \cdot \mathrm{s}^{-1}$ interval for OW buoys, considering all wind products. For SW buoys, higher differences were also observed for the lower wind speed interval, considering ASCAT-A, ASCAT$\mathrm{B}$, and ERA5 products. Best comparisons were obtained for CCMP product with oceanic water buoys $\left(\mathrm{RMSE}_{\mathrm{dir}}<23.3^{\circ}\right.$, $-0.01^{\circ}<$ bias $_{\text {dir }}<0.61^{\circ}, R_{\text {dir }}>0.91$ ), and for ASCAT-B with shelf water buoys $\left(\mathrm{RMSE}_{\mathrm{dir}}<56.6^{\circ},-0.47^{\circ}<\right.$ bias $_{\mathrm{dir}}<7.66^{\circ}$, $R_{\text {dir }}>0.59$ ), in all speed intervals.

\section{Discussion}

In the present study, data from six different ocean surface wind products were compared with in situ measurements from 15 moored buoys in oceanic and shelf waters of the Brazilian margin. In general, there is a good correspondence between the wind speeds from the simultaneous records of wind products and buoy observations (Figures 3-5 and Table S1). Without considering the BRAMS model, comparisons of simultaneous records are even better. It can be noted that ASCAT and CCMP products had slightly better results than ERA5. The spatial resolution of the databases seems to influence their performance, with the finest resolution products (satellitederived databases) showing better results than the coarser ERA5 database. Despite the removal of the systematic bias in BRAMS wind speed data, the highest $\mathrm{RMSE}_{\mathrm{spd}}$ continued to be obtained for this dataset $\left(\mathrm{RMSE}_{\mathrm{spd}}>1.56 \mathrm{~m} \cdot \mathrm{s}^{-1}\right.$ in simultaneous comparisons).

Indeed, if analysis is restricted to OW buoys, best performance is observed for CCMP product (Figure 6 and Table S2), showing the lowest errors in terms of $\mathrm{RMSE}_{\mathrm{dir}}$ and the best values of $R_{\text {spd }}$ and $R_{\text {dir }}$ for 5 or more buoys among the $8 \mathrm{OW}$ buoys compared. Although the data from the PIRATA buoys are assimilated in the generation of the CCMP dataset, these results agree with previous studies that compared CCMP and PIRATA wind data [41-43]. Suzuki et al. [42] obtained an $\mathrm{RMSE}_{\mathrm{spd}}$ value of $1.04 \mathrm{~m} \cdot \mathrm{s}^{-1}$, and Yan et al. [43] obtained RMSE $\mathrm{spd}_{\text {spd }}$, bias spd $_{\text {sp }}$ and $R_{\text {spd }}$ values of $1.29 \mathrm{~m} \cdot \mathrm{s}^{-1}, 0.24 \mathrm{~m} \cdot \mathrm{s}^{-1}$, and 0.90 , respectively. For wind direction, these authors [43] obtained $\mathrm{RMSE}_{\mathrm{dir}}=22.4^{\circ}, \operatorname{bias}_{\mathrm{dir}}=0.89^{\circ}$, and $R_{\mathrm{dir}}=0.97$. In the present study, ASCAT products showed the best results after CCMP, with a performance close to other recent comparisons [44]. The lowest errors in terms of $\mathrm{RMSE}_{\mathrm{spd}}$ for 5 of the $8 \mathrm{OW}$ buoys were obtained for ASCAT-A. Verhoef et al. [61] validated the ASCAT-A product optimized for coastal regions using in situ buoy data from the tropical oceans and along North American and European coasts. For buoys located more than $50 \mathrm{~km}$ from the coast, these authors obtained RMSE $\mathrm{spd}_{\text {of }} 2.2 \mathrm{~m} \cdot \mathrm{s}^{-1}$ and bias $_{\text {spd }}$ of $-0.29 \mathrm{~m} \cdot \mathrm{s}^{-1}$. In the present study, RMSE $\mathrm{spd}<1.25 \mathrm{~m} \cdot \mathrm{s}^{-1}$ and bias $_{\text {spd }}$ between $-0.33 \mathrm{~m} \cdot \mathrm{s}^{-1}$ and $0.25 \mathrm{~m} \cdot \mathrm{s}^{-1}$ were computed for ASCAT-A in oceanic waters. In the ASCAT-B validation report [62], bias values of $0.02 \mathrm{~m} \mathrm{~s}^{-1}$ (CMOD5.n) and $0.04 \mathrm{~m} \mathrm{~s}^{-1}$ (CMOD7) were reported, whereas in the present study, bias values varied between $-0.24 \mathrm{~m} \cdot \mathrm{s}^{-1}$ and $0.26 \mathrm{~m} \cdot \mathrm{s}^{-1}$. In the ASCAT-CDR validation report [23], bias 

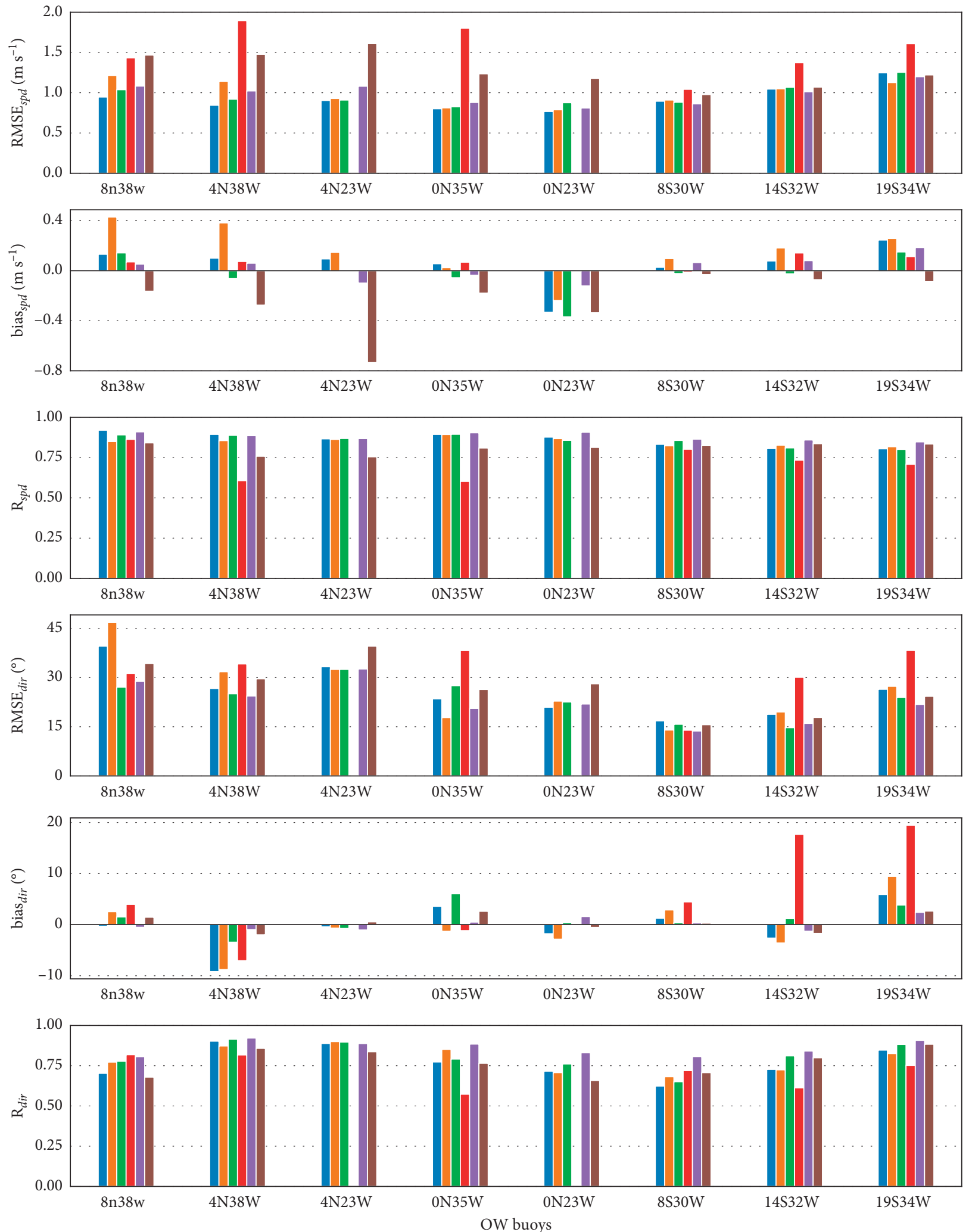

surface ocean wind products

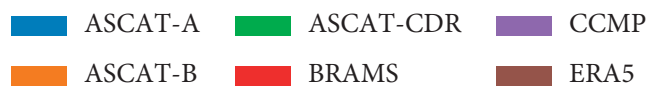

FIGURE 6: Barplots representing the statistical metrics computed for each oceanic water (OW) buoy. RMSE $\mathrm{spd}_{\text {and }}$ RMSE $\mathrm{dir}_{\text {: }}$ mean square error for wind speed and direction; bias spd $_{\text {and }}$ bias ${ }_{\mathrm{dir}}$ : bias for wind speed and direction; $R_{\mathrm{spd}}$ and $R_{\mathrm{dir}}$ : Pierson's correlation coefficient for wind speed and direction. 

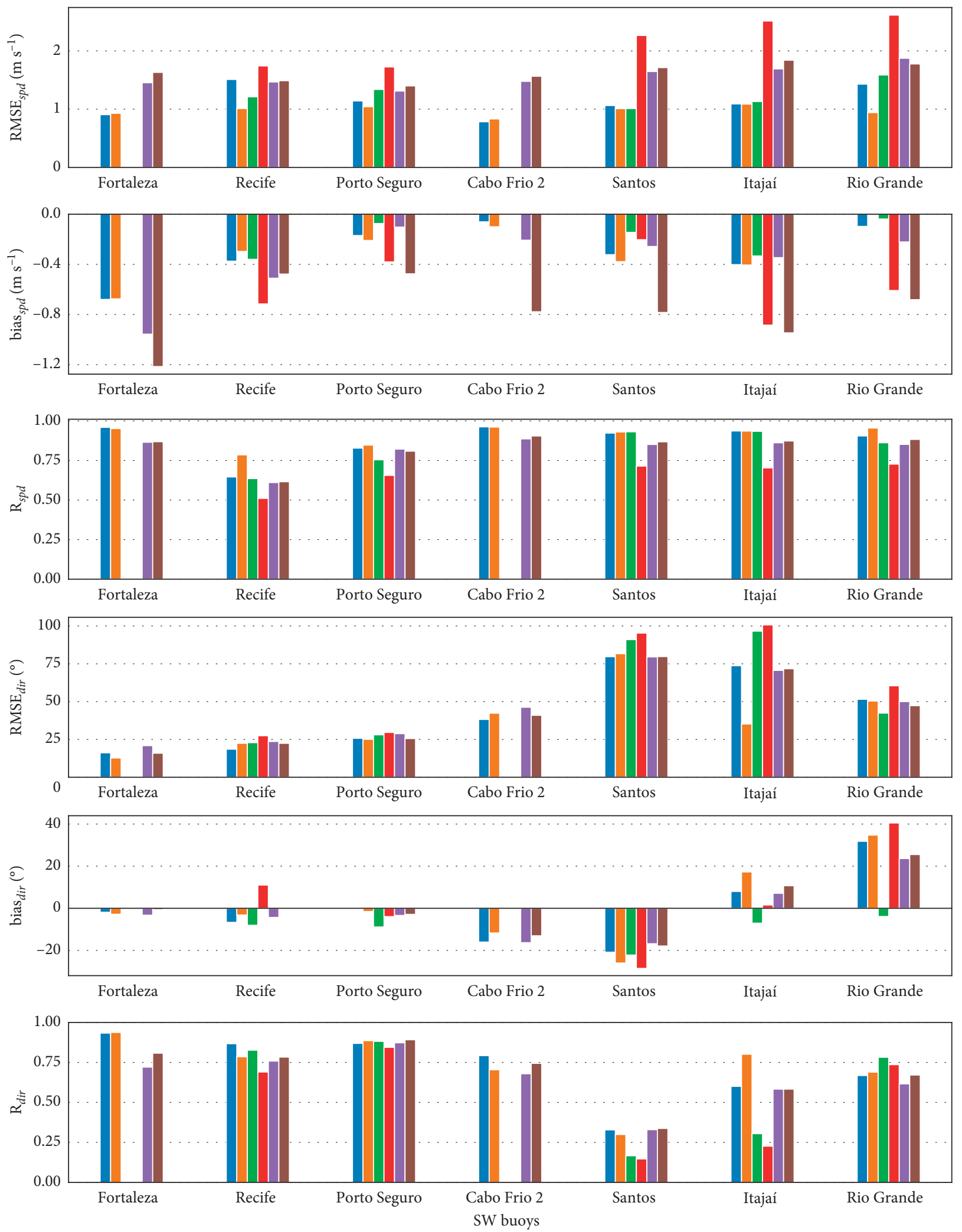

surface ocean wind products

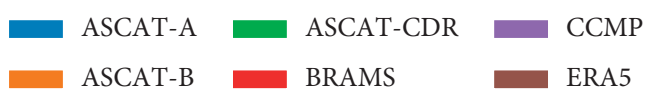

FIGURE 7: Barplots representing the statistical metrics computed for each shelf waters (SW) buoy. RMSE spd $_{\text {and RMSE }}$ :ir: mean square error for wind speed and direction; bias $_{\mathrm{spd}}$ and bias $_{\mathrm{dir}}$ : bias for wind speed and direction; $R_{\mathrm{spd}}$ and $R_{\mathrm{dir}}$ : Pierson's correlation coefficient for wind speed and direction. 

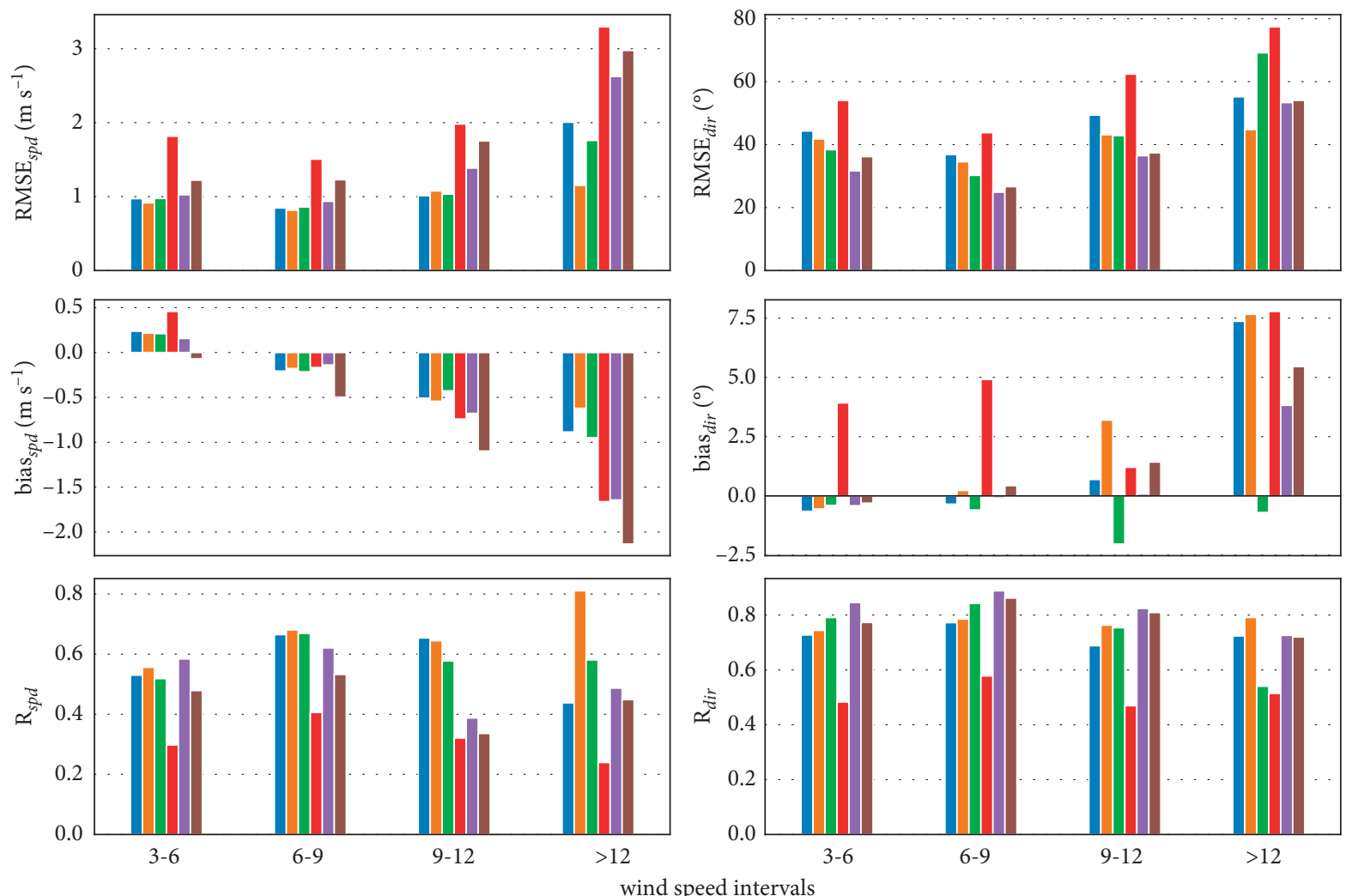

surface ocean wind products

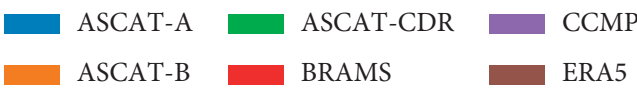

FIGURE 8: Barplots representing the statistical metrics computed for all buoys in four wind speed bins $\left(\mathrm{m} \cdot \mathrm{s}^{-1}\right)$. RMSE $\mathrm{spd}_{\mathrm{s}}$ and RMSE $\mathrm{dir}_{\mathrm{r}}$ mean square error for wind speed and direction; bias $\mathrm{spd}_{\mathrm{s}}$ and bias $_{\mathrm{dir}}$ : bias for wind speed and direction; $R_{\mathrm{spd}}$ and $R_{\mathrm{dir}}$ : Pierson's correlation coefficient for wind speed and direction.

values ranged between $-0.3 \mathrm{~m} \cdot \mathrm{s}^{-1}$ and $0.2 \mathrm{~m} \cdot \mathrm{s}^{-1}$, whereas in the present study, bias values varied between $-0.37 \mathrm{~m} \cdot \mathrm{s}^{-1}$ and $0.15 \mathrm{~m} \cdot \mathrm{s}^{-1}$.

In terms of wind direction, relatively higher differences were observed in the present study, even without considering BRAMS comparisons. Most oceanic water buoys are located in the Tropical Atlantic region where winds are more stable $[50,51]$. However, highest statistical differences were observed for shelf water buoys (Figure 2 and Table S1). Wind direction comparisons were considered more satisfactory only for SW buoys located in the northern part of the Brazilian continental margin (Figure 7 and Table S3). For Santos, Itajaí, and Rio Grande buoys located in the southern part of the study region, wind direction comparisons resulted in relatively higher differences. According to Lin et al. [74], when comparing the wind vectors classified as variable or stable, the estimated error variances of the variable winds are much higher than those of the stable winds. The southern Brazilian continental margin is well known in the literature for frequent incursions of frontal systems and relevant cyclogenetic activity, which increases the variability of the wind field in this region [52-56]. This variability pattern for these 3 buoys can be depicted from the wind roses shown in Figure 2. As an example, Figure 10 shows the differences between the wind roses of Santos buoy and ASCAT-A paired series, which are also observed for the other datasets considered in this study (Figures S2-S16 in Supplemental File). It is worth remembering that PNBOIA data (SW) are hourly averages, while PIRATA data (OW) are 10 minutes averages, which can also contribute to the relatively greater differences observed for southern shelf water buoy comparisons [75]. For satellite-derived wind products, land masking limitations can be an issue [45]. In addition, more coastal winds are very dependent on the surrounding topography, land-ocean gradients, and discontinuities.

Previous studies reported overestimations of wind speed by coastal ASCAT-A and ASCAT-B products in the Iberian, Irish, and Japanese continental shelf regions $[20,45,46]$. Takeyama et al. [46] proposed that this overestimation is inversely proportional to the distance from the coast due to increased backscatter by land contamination. However, Verhoef et al. [61] observed that the ASCAT-A product optimized for the coastal region underestimated buoy wind speed measurements in the northern hemisphere. In the present study, not only ASCAT products but all wind products underestimated buoy wind speed for shelf waters. Payan [76] observed that the ASCAT-A product overestimated buoy wind speeds in the northern hemisphere and 

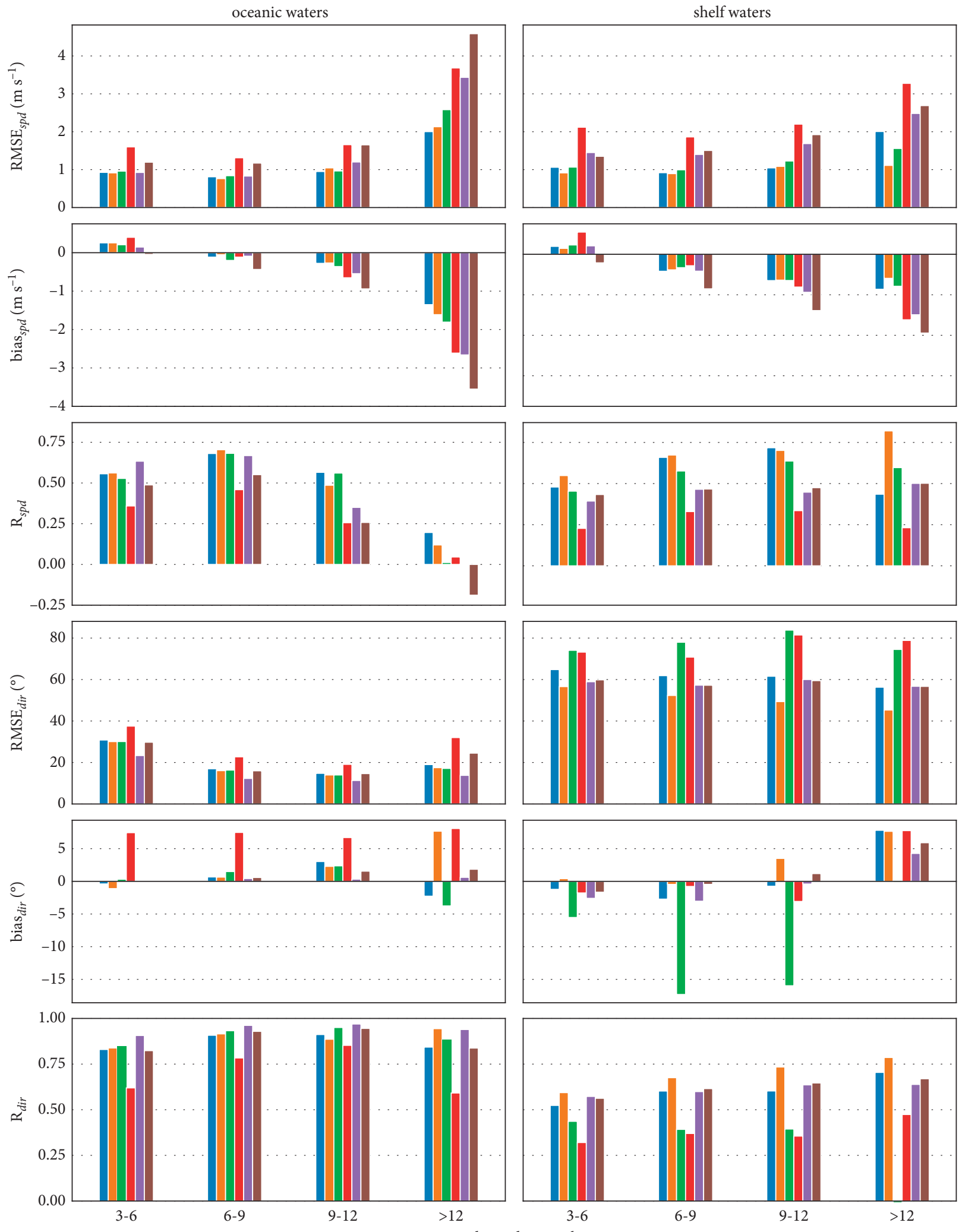

surface ocean wind products

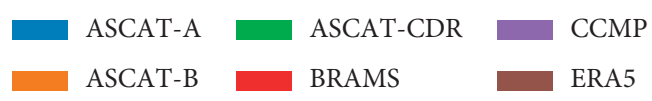

FIGURE 9: Barplots representing the statistical metrics computed for oceanic and shelf water buoys in four wind speed bins ( $\mathrm{m} \cdot \mathrm{s}^{-1}$ ). RMSE $\mathrm{spd}$ and RMSE $\mathrm{dir}_{\mathrm{di}}$ : mean square error for wind speed and direction; bias $\mathrm{spd}_{\mathrm{sp}}$ and bias $\mathrm{dir}_{\mathrm{r}}$ : bias for wind speed and direction; $R_{\mathrm{spd}}$ and $R_{\mathrm{dir}}$ : Pierson's correlation coefficient for wind speed and direction. 


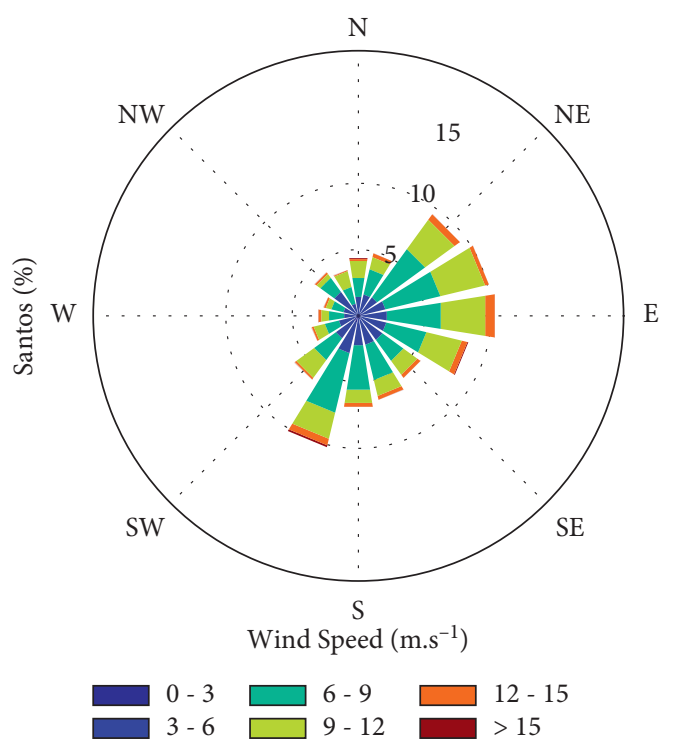

(a)

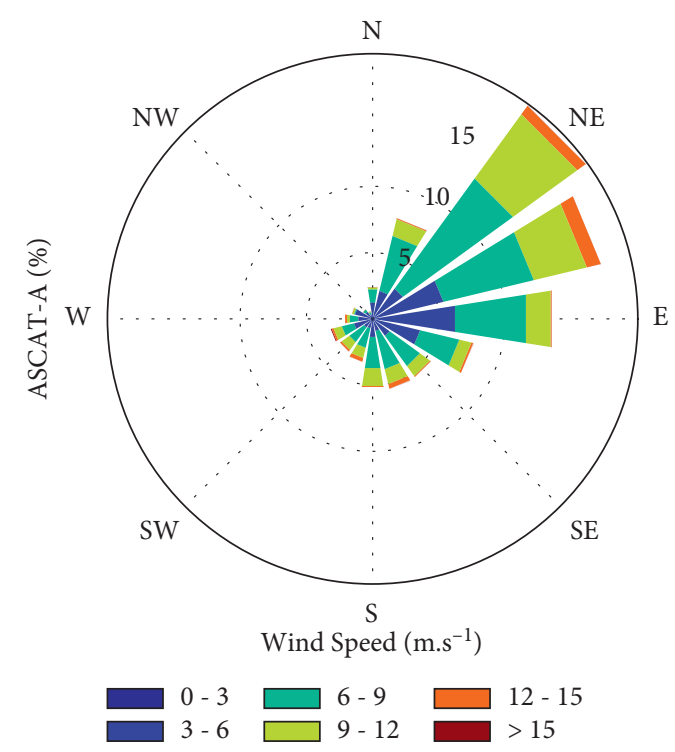

(b)

Figure 10: Wind roses of the Santos buoy and ASCAT-A paired series (Please see Figures S2-S16 for all buoys and wind datasets).

underestimated speeds measured in the southern hemisphere. In general, the comparisons of wind speed obtained in the present study for shelf waters agree with previous studies. The best performances are distributed between ASCAT products (Figure 7, Table S3). CCMP and ERA5 also show good performance for wind speed, with exception for Recife buoy, which is the closest to the coast $(35 \mathrm{~km})$.

Regarding the comparisons by wind speed intervals (Figures 8 and 9 and Table S4), ASCAT-A and ASCAT-B showed a better statistical performance in terms of RMSE and $R$, considering all datasets. In general, the lowest $\mathrm{RMSE}_{\mathrm{spd}}$ and higher $R_{\mathrm{spd}}$ values were observed in the 6-9 $\mathrm{m} \cdot \mathrm{s}^{-1}$ interval. The poor wind speed accuracy for interval $>12 \mathrm{~m} \cdot \mathrm{s}^{-1}$ for OW buoys can be related to the relatively low amount of data recorded for this wind speed interval, as seen in the wind roses shown in Figure 2. Almost all wind products overestimated speeds between $3 \mathrm{~m} \cdot \mathrm{s}^{-1}$ and $6 \mathrm{~m} \cdot \mathrm{s}^{-1}$ and underestimated speeds $>6 \mathrm{~m} \cdot \mathrm{s}^{-1}$, so that as wind speed increases, the negative bias increases proportionally. According to Carvalho et al. [19], weaker winds produce low amounts of backscatter, which scatterometers have difficulties in measuring. Stronger winds can only produce proportional backscatter in the ocean surface until a certain threshold, after which no more backscatter is produced even if the wind speed keeps increasing. Regarding wind direction, best comparisons with OW buoys were obtained for CCMP product. High values of RMSE $\mathrm{E}_{\text {dir }}$ and low correlations for SW buoys can be related to subcell wind variability in southern Brazilian shelf, as mentioned above [74]. In general, the statistical performance for wind direction increases towards the higher speed intervals. According to Chakraborty et al. [37], the scatterometer errors associated with wind direction are highly random and are dependent on wind speed. In general, the lower the wind speeds, the higher the wind direction errors.

\section{Conclusions}

This study evaluates and compares satellite-derived ocean surface wind data (ASCAT-A and ASCAT-B scatterometers), reanalysis (ERA5), BRAMS-modelled surface winds, and a satellite-reanalysis-buoy-blended product (Cross-Calibrated Multi-Platform ocean wind vectors), to analyze the performance of these datasets in representing the in situ measurements obtained by moored buoys along the Brazilian margin. The results presented here can be of great value for climate and oceanographic studies, among others, especially where in situ measured wind data are not available or are insufficient, therefore requiring alternative sources of wind data to be considered.

Ocean surface wind estimations obtained with ASCAT scatterometer optimized for coastal regions and with a spatial resolution of $12.5 \mathrm{~km}$ are the ones that best represent the in situ wind speed, with the lower $\mathrm{RMSE}_{\text {spd }}$ $\left(<1.59 \mathrm{~m} \cdot \mathrm{s}^{-1}\right)$, lower bias spd $\left( \pm 0.68 \mathrm{~m} \cdot \mathrm{s}^{-1}\right)$, and higher correlation $(>0.75)$ in relation to the other products considered in the study. However, CCMP product also showed a good statistical comparison with in situ buoy data $\left(\right.$ RMSE $<1.87 \mathrm{~m} \cdot \mathrm{s}^{-1}$, bias $\left.\pm 0.96 \mathrm{~m} \cdot \mathrm{s}^{-1}, R>0.82\right)$, as well as ERA5 $\quad\left(\mathrm{RMSE}_{\mathrm{spd}}<1.84 \mathrm{~m} \cdot \mathrm{s}^{-1}, \quad \operatorname{bias}_{\mathrm{spd}} \pm 1.21 \mathrm{~m} \cdot \mathrm{s}^{-1}\right.$, $R_{\text {spd }}>0.76$ ). Among all the compared ocean surface wind products, BRAMS is the least able to represent the wind field $\left(\mathrm{RMSE}_{\mathrm{spd}}>1.04 \mathrm{~m} \cdot \mathrm{s}^{-1}\right.$, bias $\left._{\mathrm{spd}} \pm 2.89, R_{\mathrm{spd}}<0.87\right)$. In regions with more variable winds, as in the southern Brazilian continental margin, the estimation of wind direction is more susceptible to errors ( $\operatorname{RMSE}_{\mathrm{dir}}>42.4^{\circ}$ ).

Considering the relatively higher temporal resolution of ERA5 and CCMP products ( 1 and 6 hours, respectively), and the extension of the available time series ( $>30$ years), it is suggested to use these datasets to build a regional climatology and to analyze the space-time variability of wind fields 
in the study region. Nevertheless, there are seven orbital scatterometers operating currently [77-81]. This number of operational scatterometers has been increasing in recent years and in near future. Once the scatterometers can give winds within 6 hours over the regional ocean, it may be good to use combined winds from multiple scatterometers. The derived information for such satellite constellation and alternative sources could be useful for several applications, as on the estimation of the potential wind power generation in the Brazilian margin region.

\section{Data Availability}

In situ buoy wind data can be accessed at https:// www.marinha.mil.br/chm/dados-do-goos-brasil/pnboiamapa and https://www.pmel.noaa.gov/tao/drupal/disdel/; scatterometer wind data at projects.knmi.nl/scatterometer/; blended CCMP data at http://www.remss.com/measurements/ccmp/; and ERA5 reanalysis data at www.ecmwfint/ en/forecasts/datasets/archive-datasets/reanalysis-datasets/ era5. The authors agree to make data and materials supporting the results presented in the manuscript available upon reasonable request.

\section{Conflicts of Interest}

The authors declare that there are no conflicts of interest regarding the publication of this paper.

\section{Acknowledgments}

The authors would like to thank the Brazilian Navy Hydrography Centre, INPE's Weather and Climate Forecast Centre, the Pacific Marine Environmental Laboratory, the European Organization for the Exploitation of Meteorological Satellites, the Royal Netherlands Meteorological Institute, and the European Centre for Medium Range Weather Forecasts for the data used in this study. This work was supported by the Coordenação de Aperfeiçoamento de Pessoal de Nível Superior (CAPES), Brazil (Grant Finance Code 001). VGP was supported by CAPES (PROEX 0487/ 1681024).

\section{Supplementary Materials}

The supporting information consists of detailed tables and figures of our results that are mentioned and discussed in the text of the Results and Discussion sections. (Supplementary Materials)

\section{References}

[1] M. Bourassa, A. Stoffelen, H. Bonekamp et al., "Remotely sensed winds and wind stresses for marine forecasting and ocean modeling," in Proceedings of 2009 OceanObs: Sustained Ocean Observations and Information for Society, vol. 2, Venice, Italy, September 2009.

[2] J. Kämpf and P. Chapman, "Seasonal wind-driven coastal upwelling systems," in Upwelling Systems of the World, Chapter 8, pp. 315-361, Springer, Berlin, Germany, 2016.
[3] C. Aguirre, S. García-Loyola, G. Testa, D. Silva, L. Farias, and J. É. Tremblay, "Insight into anthropogenic forcing on coastal upwelling off south-central Chile," Elementa Science of the Anthropocene, vol. 6, no. 59, 2018.

[4] H. Demarcq, "Trends in primary production, sea surface temperature and wind in upwelling systems (1998-2007)," Progress in Oceanography, vol. 83, no. 1-4, pp. 376-385, 2009.

[5] M. G. Jacox, E. L. Hazen, and S. J. Bograd, "Optimal environmental conditions and anomalous ecosystem responses: constraining bottom-up controls of phytoplankton biomass in the California current system," Scientific Reports, vol. 6, Article ID 27612, 2016.

[6] Y. Amitai, Y. Ashkenazy, and H. Gildor, "The effect of windstress over the eastern Mediterranean on deep-water formation in the Adriatic sea," Deep Sea Research Part II: Topical Studies in Oceanography, vol. 164, pp. 5-13, 2019.

[7] J. L. Bullister, M. Rhein, and C. Mauritzen, "Deepwater formation," in Ocean Circulation and Climate-A 21st Century Perspective, vol. 103, pp. 227-253, Academic Press, Cambridge, MA, USA, 2013.

[8] W. G. Large and S. Pond, "Open ocean momentum flux measurements in moderate to strong winds," Journal of Physical Oceanography, vol. 11, no. 3, pp. 324-336, 1981.

[9] D. B. Chelton, M. G. Schlax, M. H. Freilich, and R. F. Milliff, "Satellite measurements reveal persistent small-scale features in ocean winds," Science, vol. 303, no. 5660, pp. 978-983, 2004.

[10] C. Fairall, B. Barnier, and D. I. Berry, "Observations to quantify air-sea fluxes and their role in climate variability and predictability," in Proceedings of 2009 OceanObs: Sustained Ocean Observations and Information for Society, vol. 2, Venice, Italy, September 2009.

[11] J. P. Machado, F. Justino, and L. P. Pezzi, "Impacts of wind stress changes on the global heat transport, baroclinic instability, and the thermohaline circulation," Advances in Meteorology, vol. 2016, Article ID 2089418, 15 pages, 2016.

[12] W. T. Liu, W. Tang, and X. Xie, "Wind power distribution over the ocean," Geophysical Research Letters, vol. 35, no. 13, 2008.

[13] J. Vogelzang and A. Stoffelen, "Scatterometer wind vector products for application in meteorology and oceanography," Journal of Sea Research, vol. 74, pp. 16-25, 2012.

[14] C. M. Risien and D. B. Chelton, "A satellite-derived climatology of global ocean winds," Remote Sensing of Environment, vol. 105, no. 3, pp. 221-236, 2006.

[15] D. Dee, J. Fasullo, D. Shea, J. Walsh, and NCAR, The Climate Data Guide: Atmospheric Reanalysis: Overview \& Comparison Tables, National Center for Atmospheric Research, Boulder, CO, USA, 2016, https://climatedataguide.ucar.edu/climatedata/atmospheric-reanalysis-overview-comparison-tables.

[16] A. J. Wallcraft, A. B. Kara, C. N. Barron, E. J. Metzger, R. L. Pauley, and M. A. Bourassa, "Comparisons of monthly mean $10 \mathrm{~m}$ wind speeds from satellites and NWP products over the global ocean," Journal of Geophysical Research: Atmospheres, vol. 114, no. 16, 2009.

[17] S. R. Smith, P. J. Hughes, and M. A. Bourassa, "A comparison of nine monthly air-sea flux products," International Journal of Climatology, vol. 31, no. 7, pp. 1002-1027, 2011.

[18] E. Kalnay, Atmospheric Modeling, Data Assimilation and Predictability, Cambridge University Press, New York, NY, USA, 2003.

[19] D. Carvalho, A. Rocha, M. Gómez-Gesteira, and C. Silva Santos, "Comparison of reanalyzed, analyzed, satellite-retrieved and NWP modelled winds with buoy data along the Iberian 
Peninsula coast," Remote Sensing of Environment, vol. 152, pp. 480-492, 2014.

[20] D. Carvalho, A. Rocha, M. Gómez-Gesteira, and C. Silva Santos, "Offshore winds and wind energy production estimates derived from ASCAT, OSCAT, numerical weather prediction models and buoys-a comparative study for the Iberian Peninsula Atlantic coast," Renewable Energy, vol. 102, pp. 433-444, 2017.

[21] M. A. Bourassa, A. Stoffelen, H. Bonekamp et al., "Remotely sensed winds and wind stresses for marine forecasting and ocean modeling," Frontiers in Marine Science, vol. 6443 pages, 2019.

[22] F. J. Wentz, L. Ricciardulli, E. Rodriguez et al., "Evaluating and extending the ocean wind climate data record," IEEE Journal of Selected Topics in Applied Earth Observations and Remote Sensing, vol. 10, no. 5, pp. 2165-2185, 2017.

[23] A. Verhoef, J. Vogelzang, and A. Stoffelen, ASCAT L2 Winds Data Record Validation Report, Royal Netherlands Meteorological Institute, De Bilt, Netherlands, 2016.

[24] N. Ebuchi, H. C. Graber, and M. J. Caruso, "Evaluation of wind vectors observed by QuikSCAT/SeaWinds using ocean buoy data," Journal of Atmospheric and Oceanic Technology, vol. 19, no. 12, pp. 2049-2062, 2002.

[25] F. M. Pimenta, A. R. Silva, A. T. Assireu, V. d. S. e. Almeida, and O. R. Saavedra, "Brazil offshore wind resources and atmospheric surface layer stability," Energies, vol. 12, no. 21, p. 4195, 2019.

[26] A. B. Villas Bôas, F. Ardhuin, A. Ayet et al., "Integrated observations of global surface winds, currents, and waves: requirements and challenges for the next decade," Frontiers in Marine Science, vol. 6, no. 425, 2019.

[27] D. B. Chelton, M. H. Freilich, J. M. Sienkiewicz, and J. M. Von Ahn, "On the use of QuikSCAT scatterometer measurements of surface winds for marine weather prediction," Monthly Weather Review, vol. 134, no. 8, pp. 2055-2071, 2006.

[28] D. Halpern, "Offshore Ekman transport and Ekman pumping off Peru during the 1997-1998 El Nino," Geophysical Research Letters, vol. 29, no. 5, pp. 1-19, 2002.

[29] D. Chelton and S.-P. Xie, "Coupled ocean-atmosphere interaction at oceanic mesoscales," Oceanography, vol. 23, no. 4, pp. 52-69, 2010.

[30] A. Bentamy and D. C. Fillon, "Gridded surface wind fields from Metop/ASCAT measurements," International Journal of Remote Sensing, vol. 33, no. 6, pp. 1729-1754, 2012.

[31] A. Bentamy, S. A. Grodsky, A. Elyouncha, B. Chapron, and F. Desbiolles, "Homogenization of scatterometer wind retrievals," International Journal of Climatology, vol. 37, no. 2, pp. 870-889, 2017.

[32] N. Ebuchi, "Intercomparison of four ocean vector wind products from OceanSat-2 scatterometer," in Proceedings of the 2013 IEEE International Geoscience and Remote Sensing Symposium-IGARSS 2013, Melbourne, Australia, 2013.

[33] Z. Wang, A. Stoffelen, B. Zhang, Y. He, W. Lin, and X. Li, "Inconsistencies in scatterometer wind products based on ASCAT and OSCAT-2 collocations," Remote Sensing of Environment, vol. 225, pp. 207-216, 2019.

[34] M. C. Baptista, "An analysis of the surface wind field over the tropical and southern Atlantic ocean using data from the ERS scatterometer," Master's thesis, INPE, San Jose dos Campos, Brazil, 2000.

[35] A. Bentamy, D. Croize-Fillon, and C. Perigaud, "Characterization of ASCAT measurements based on buoy and QuikSCAT wind vector observations," Ocean Science, vol. 4, no. 4, pp. 265-274, 2008.
[36] F. Pimenta, W. Kempton, and R. Garvine, "Combining meteorological stations and satellite data to evaluate the offshore wind power resource of southeastern Brazil," Renewable Energy, vol. 33, no. 11, pp. 2375-2387, 2008.

[37] A. Chakraborty, R. Kumar, and A. Stoffelen, "Validation of ocean surface winds from the OCEANSAT-2 scatterometer using triple collocation," Remote Sensing Letters, vol. 4, no. 1, pp. 84-93, 2013.

[38] D. S. Dukhovskoy, M. A. Bourassa, G. N. Petersen, and J. Steffen, "Comparison of the ocean surface vector winds from atmospheric reanalysis and scatterometer-based wind products over the Nordic seas and the northern north Atlantic and their application for ocean modeling," Journal of Geophysical Research: Oceans, vol. 122, no. 3, pp. 1943-1973, 2017.

[39] J. Yang and J. Zhang, "Comparison of Oceansat-2 scatterometer wind data with global moored buoys and ASCAT observation," Advances in Meteorology, vol. 2019, Article ID 1651267, 9 pages, 2019.

[40] Z. Wang, A. Stoffelen, J. Zou et al., "Validation of new sea surface wind products from scatterometers onboard the HY2B and MetOp-C satellites," IEEE Transactions on Geoscience and Remote Sensing, vol. 58, no. 6, pp. 4387-4394, 2020.

[41] A. Okuro and M. Kubota, "Inter-comparison of daily mean sea surface wind speeds in various global high-resolution products," Journal of The Remote Sensing Society of Japan, vol. 34, no. 3, pp. 177-196, 2014.

[42] N. Suzuki, M. Konda, K. Kutsuwada, and K. Utsunomiya, "Comparison of the accuracy of various global wind speed datasets obtained from satellites and reanalyses," Journal of Advanced Marine Science and Technology Society, vol. 24, no. 2, pp. 31-37, 2018.

[43] Q. Yan, J. Zhang, J. Meng, J. Wang, and C. Fan, "Use of an optimum interpolation method to construct a high-resolution global ocean surface vector wind dataset from active scatterometers and passive radiometers," International Journal of Remote Sensing, vol. 38, no. 20, pp. 5569-5591, 2017.

[44] A. Modi, S. K. Munaka, R. Harikumar, T. B. Nair, and K. Srinivas, "Evaluation of winds from SCATSAT-1 and ASCAT using buoys in the Indian ocean," Journal of the Indian Society of Remote Sensing, vol. 49, pp. 1915-1925, 2021.

[45] T. Remmers, F. Cawkwell, C. Desmond, J. Murphy, and E. Politi, "The potential of advanced scatterometer (ASCAT) $12.5 \mathrm{~km}$ coastal observations for offshore wind farm site selection in Irish waters," Energies, vol. 12, no. 2, p. 206, 2019.

[46] Y. Takeyama, T. Ohsawa, S. Shimada, K. Kozai, K. Kawaguchi, and T. Kogaki, "Assessment of the offshore wind resource in Japan with the ASCAT microwave scatterometer," International Journal of Remote Sensing, vol. 40, no. 3, pp. 1200-1216, 2019.

[47] B. M. Castro, F. P. Brandini, M. Dottori, and J. F. Fortes, “A Amazônia Azul: recursos e preservação," Revista USP, vol. 113, pp. 7-26, 2017.

[48] M. S. Reboita, T. Ambrizzi, B. A. Silva, R. F. Pinheiro, and R. P. Da Rocha, "The south Atlantic subtropical anticyclone: present and future climate," Frontiers in Earth Science, vol. 7, p. 8, 2019.

[49] X. Sun, K. H. Cook, and E. K. Vizy, "The south Atlantic subtropical high: climatology and interannual variability," Journal of Climate, vol. 30, no. 9, pp. 3279-3296, 2017.

[50] S. Hastenrath, Climate Dynamics of the Tropics, Vol. 8, Springer Science \& Business Media, Berlin, Germany, 1991.

[51] A. Melo, I. A. Cavalcanti, and P. Souza, "Zona de convergência intertropical do Atlântico," in Tempo e Clima no BrasilOficina de Textos, Sao Paulo, Brazil, 2009. 
[52] J. M. Wallace and P. V. Hobbs, Atmospheric Science: An Introductory Survey, Vol. 92, Elsevier, Amsterdam, Netherlands, 2006.

[53] I. A. Cavalcanti and V. E. Kousky, "Frentes frias sobre o Brasil," in Tempo e Clima no Brasil, pp. 135-147, Oficina de Textos, Sao Paulo, Brazil, 2009.

[54] B. J. Hoskins and K. I. Hodges, "A new perspective on southern hemisphere storm tracks," Journal of Climate, vol. 18, no. 20, pp. 4108-4129, 2005.

[55] M. S. Reboita, M. A. Gan, R. P. d. Rocha, and T. Ambrizzi, "Regimes of precipitation in south America: a bibliographical review," Brazilian Journal of Meteorology, vol. 25, no. 2, pp. 185-204, 2010.

[56] L. M. V. Carvalho, C. Jones, and B. Liebmann, "The south Atlantic convergence zone: intensity, form, persistence, and relationships with intraseasonal to interannual activity and extreme rainfall," Journal of Climate, vol. 17, no. 1, pp. 88-108, 2004.

[57] W. T. Liu, K. B. Katsaros, and J. A. Businger, "Bulk parameterization of air-sea exchanges of heat and water vapor including the molecular constraints at the interface," Journal of the Atmospheric Sciences, vol. 36, no. 9, pp. 1722-1735, 1979.

[58] S. D. Smith, "Coefficients for sea surface wind stress, heat flux, and wind profiles as a function of wind speed and temperature," Journal of Geophysical Research, vol. 93, no. C12, pp. 15467-15472, 1988.

[59] H. Hersbach, A. Stoffelen, and S. De Haan, "The improved C-band geophysical model function CMOD5," in Proceedings of the 2005 Envisat \& ERS Symposium, Salzburg, Austria, 2005.

[60] A. Stoffelen, J. A. Verspeek, J. Vogelzang, and A. Verhoef, "The CMOD7 geophysical model function for ASCAT and ERS wind retrievals," IEEE Journal of Selected Topics in Applied Earth Observations and Remote Sensing, vol. 10, no. 5, pp. 2123-2134, 2017.

[61] A. Verhoef, M. Portabella, and A. Stoffelen, "High-resolution ASCAT scatterometer winds near the coast," IEEE Transactions on Geoscience and Remote Sensing, vol. 50, no. 7, pp. 2481-2487, 2012.

[62] A. Verhoef and A. Stoffelen, ASCAT Coastal Winds Validation Report, Royal Netherlands Meteorological Institute, De Bilt, Netherlands, 2013.

[63] R. Atlas, R. N. Hoffman, J. Ardizzone et al., “A cross-calibrated, multiplatform ocean surface wind velocity product for meteorological and oceanographic applications," Bulletin of the American Meteorological Society, vol. 92, no. 2, pp. 157-174, 2011.

[64] F. J. Wentz, J. Scott, R. Hoffman, M. Leidner, R. Atlas, and J. Ardizzone, "Remote sensing systems cross-calibrated multiplatform (CCMP) 6-hourly ocean vector wind analysis product on $0.25 \mathrm{deg}$ grid," 2015, https://www.remss.com/ measurements/ccmp/.

[65] R. Atlas, R. N. Hoffman, S. C. Bloom, J. C. Jusem, and J. Ardizzone, "A multiyear global surface wind velocity dataset using SSM/I wind observations," Bulletin of the American Meteorological Society, vol. 77, no. 5, pp. 869-882, 1996.

[66] R. N. Hoffman, "SASS wind ambiguity removal by direct minimization," Monthly Weather Review, vol. 110, no. 5, pp. 434-445, 1982.

[67] R. N. Hoffman, "SASS wind ambiguity removal by direct minimization. Part II: use of smoothness and dynamical constraints," Monthly Weather Review, vol. 112, no. 9, pp. 1829-1852, 1984.
[68] S. R. Jammalamadaka and A. Sengupta, Topics in Circular Statistics, Vol. 5, World Scientific, Singapore, 2001.

[69] K. E. Taylor, "Summarizing multiple aspects of model performance in a single diagram," Journal of Geophysical Research: Atmospheres, vol. 106, no. 7, pp. 7183-7192, 2001.

[70] M. P. Byrne, A. G. Pendergrass, A. D. Rapp, and K. R. Wodzicki, "Response of the intertropical convergence zone to climate change: location, width, and strength," Current Climate Change Reports, vol. 4, no. 4, pp. 355-370, 2018.

[71] M. B. Switanek, P. A. Troch, C. L. Castro et al., "Scaled distribution mapping: a bias correction method that preserves raw climate model projected changes," Hydrology and Earth System Sciences, vol. 21, no. 6, pp. 2649-2666, 2017.

[72] C. Anderson, H. Bonekamp, C. Duff, J. Figa-Saldana, and J. J. W. Wilson, "Analysis of ASCAT ocean backscatter measurement noise," IEEE Transactions on Geoscience and Remote Sensing, vol. 50, no. 7, pp. 2449-2457, 2012.

[73] L. Zeng and R. A. Brown, "Scatterometer observations at high wind speeds," Journal of Applied Meteorology, vol. 37, no. 11, pp. 1412-1420, 1998.

[74] W. Lin, M. Portabella, A. Stoffelen, J. Vogelzang, and A. Verhoef, "ASCAT wind quality under high subcell wind variability conditions," Journal of Geophysical Research: Oceans, vol. 120, no. 8, pp. 5804-5819, 2015.

[75] J. C. May and M. A. Bourassa, "Quantifying variance due to temporal and spatial difference between ship and satellite winds," Journal of Geophysical Research: Oceans, vol. 116, 2011.

[76] C. Payan, "Improvements in the use of scatterometer winds in the operational NWP system at Météo-France," in Proceedings of the 2010 International Winds Workshop, vol. 10, pp. 22-26, Tokyo, Japan, 2010.

[77] A. Verhoef and A. Stoffelen, ASCAT Wind Validation Report, Royal Netherlands Meteorological Institute, De Bilt, Netherlands, 2018.

[78] J. Verspeek, A. Verhoef, and A. Stoffelen, ASCAT-C Wind Product Calibration and Validation, Royal Netherlands Meteorological Institute, De Bilt, Netherlands, 2019.

[79] S. Singh, R. K. Tiwari, H. S. Gusain, and V. Sood, "Potential applications of SCATSAT-1 satellite sensor: a systematic review," IEEE Sensors Journal, vol. 20, no. 21, pp. 12459-12471, 2020.

[80] H. Wang, J. Zhu, M. Lin, Y. Zhang, and Y. Chang, "Evaluating Chinese HY-2B HSCAT ocean wind products using buoys and other scatterometers," IEEE Geoscience and Remote Sensing Letters, vol. 17, no. 6, pp. 923-927, 2020.

[81] R. E. N. Yueming, LM-4B Successfully Launched HY-2C Satellite, China Aerospace Science and Technology Corporation, Beijing, China, 2020. 